\title{
Uptake, Trapping, and Release of Organometallic Cations in Redox- Active Cationic Hosts
}

\author{
Iram F. Mansoor, Kaitlyn G. Dutton, Daniel A. Rothschild, Richard C. Remsing, and Mark C. Lipke* \\ Department of Chemistry and Chemical Biology, Rutgers, The State University of New Jersey, 123 Bevier Road, Pisca- \\ taway, New Jersey 08854, United States
}

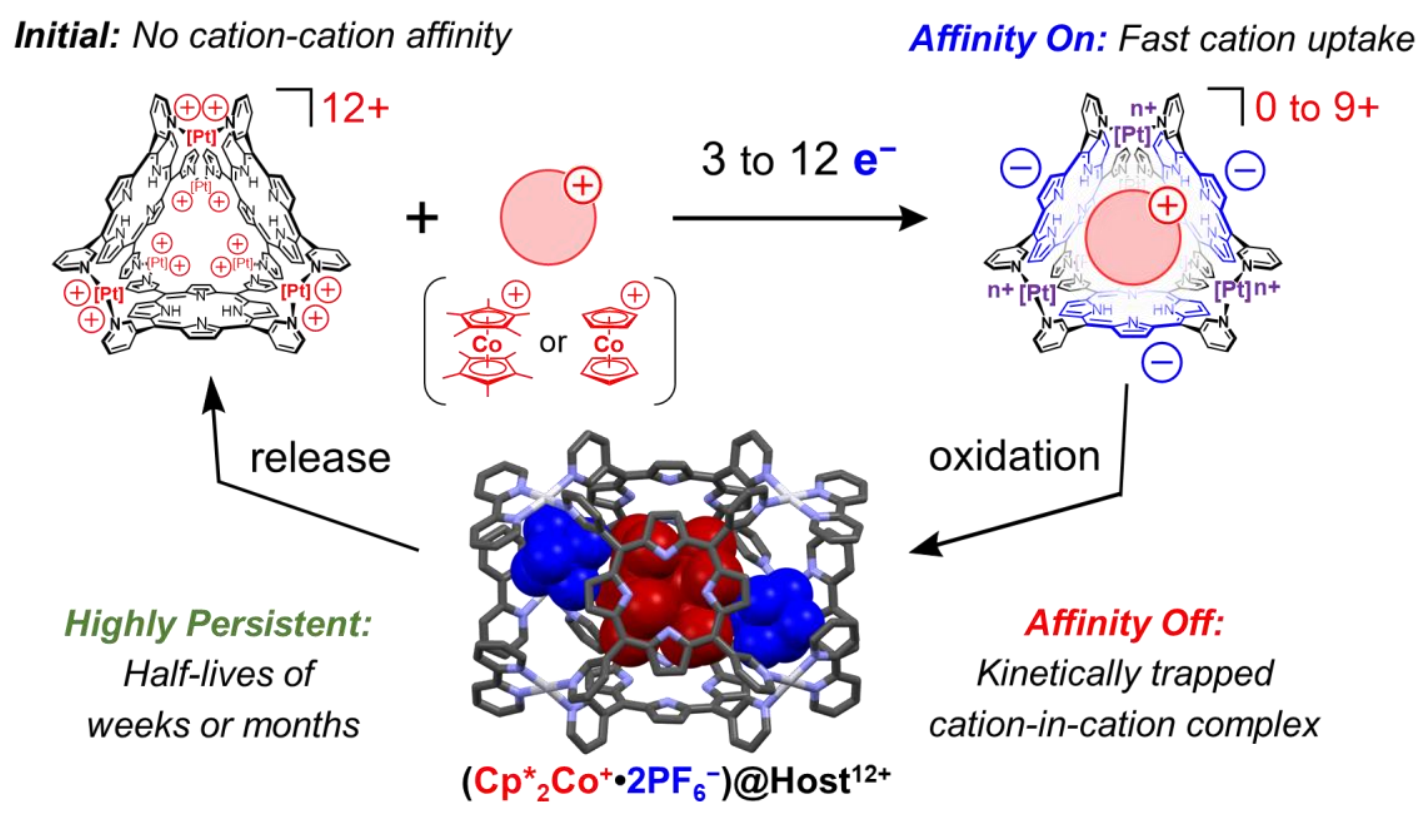

\begin{abstract}
The host-guest chemistry of metal-organic nanocages is typically driven by thermodynamically favorable interactions with their guests, such that uptake and release of guests can be controlled by switching affinity on/off. Herein, we achieve this effect by reducing porphyrin-walled cationic nanoprisms $\mathbf{1 a}^{\mathbf{1 2 +}}$ and $\mathbf{1 b}^{\mathbf{1 2 +}}$ to zwitterionic states that rapidly uptake organometallic cations $\mathrm{Cp}_{2}{ }_{2} \mathrm{Co}^{+}$or $\mathrm{Cp}_{2} \mathrm{Co}^{+} . \mathrm{Cp}_{2}{ }_{2} \mathrm{Co}^{+}$binds strongly $\left(K_{\mathrm{a}}=1.3 \times 10^{3} \mathrm{M}^{-1}\right)$ in the neutral state $\mathbf{1 a}^{\mathbf{0}}$ of host $\mathbf{1 a}^{\mathbf{1 2 +}}$, which has its three porphyrin walls doubly reduced and its six (bipy)Pt ${ }^{2+}$ linkers singly reduced. The less-reduced states of the host $\mathbf{1 a}^{3+}$ and $\mathbf{1 a}^{9+}$ also bind $\mathrm{Cp}^{*}{ }_{2} \mathrm{Co}^{+}$, though with lower affinities. The smaller $\mathrm{Cp}_{2} \mathrm{Co}^{+}$cation binds strongly $\left(K_{\mathrm{a}}=1.7 \mathrm{x}\right.$ $10^{3} \mathrm{M}^{-1}$ ) in the $3 \mathrm{e}^{-}$reduced state $\mathbf{1 b}^{\mathbf{9}+}$ of (tmeda) $\mathrm{Pt}^{2+}$ linked host $\mathbf{1 b}^{\mathbf{1 2 +}}$. Upon reoxidation of the hosts with Ag $\mathrm{g}^{+}$, the guests become trapped to provide unprecedented metastable cation-in-cation complexes $\mathbf{C p}^{*} \mathbf{C o}^{+} @ \mathbf{1 a}^{\mathbf{1 2 +}}$ and $\mathbf{C p}_{2} \mathbf{C o}^{+} @ \mathbf{1} \mathbf{b}^{\mathbf{1 2 +}}$ that persist for $>1$ month. Thus, dramatic kinetic effects reveal a way to confine the guests in thermodynamically unfavorable environments. Experimental and DFT studies indicate that $\mathrm{PF}_{6}{ }^{-}$anions kinetically stabilize $\mathbf{C p}^{*}{ }_{2} \mathbf{C o}^{+} @ 1 \mathbf{a}^{12+}$ through electrostatic interactions and by influencing conformational changes of the host that open and close its apertures. However, when $\mathbf{C p}^{*} \mathbf{C o}^{+} @ 1 \mathbf{a}^{12+}$ was prepared using ferrocenium $\left(\mathrm{Fc}^{+}\right)$instead of $\mathrm{Ag}^{+}$to reoxidize the host, dissociation was accelerated $>200$ fold even though neither $\mathrm{Fc}^{+}$nor $\mathrm{Fc}$ have any competing affinity for $\mathbf{1 a}^{\mathbf{1 2 +}}$. This finding shows that metastable host-guest complexes can respond to subtler stimuli than are required to induce guest release from thermodynamically favorable complexes.
\end{abstract}




\title{
Uptake, Trapping, and Release of Organometallic Cations in Redox- Active Cationic Hosts
}

\author{
Iram F. Mansoor, Kaitlyn G. Dutton, Daniel A. Rothschild, Richard C. Remsing, and Mark C. Lipke* \\ Department of Chemistry and Chemical Biology, Rutgers, The State University of New Jersey, 123 Bevier Road, Pisca- \\ taway, New Jersey 08854, United States
}

\begin{abstract}
The host-guest chemistry of metal-organic nanocages is typically driven by thermodynamically favorable interactions with their guests, such that uptake and release of guests can be controlled by switching affinity on/off. Herein, we achieve this effect by reducing porphyrin-walled cationic nanoprisms $\mathbf{1 a}^{\mathbf{1 2 +}}$ and $\mathbf{1 b}^{\mathbf{1 2 +}}$ to zwitterionic states that rapidly uptake organometallic cations $\mathrm{Cp}^{*}{ }_{2} \mathrm{Co}^{+}$or $\mathrm{Cp}_{2} \mathrm{Co}^{+}$. $\mathrm{Cp}^{*}{ }_{2} \mathrm{Co}^{+}$binds strongly $\left(K_{\mathrm{a}}=1.3 \times 10^{3} \mathrm{M}^{-1}\right)$ in the neutral state $\mathbf{1 a}^{\mathbf{0}}$ of host $\mathbf{1 a}^{12+}$, which has its three porphyrin walls doubly reduced and its six (bipy) $\mathrm{Pt}^{2+}$ linkers singly reduced. The less-reduced states of the host $\mathbf{1 a}^{3+}$ and $1 \mathbf{a}^{9+}$ also bind $\mathrm{Cp}_{2}{ }_{2} \mathrm{Co}^{+}$, though with lower affinities. The smaller $\mathrm{Cp}_{2} \mathrm{Co}^{+}$cation binds strongly $\left(K_{\mathrm{a}}=1.7 \mathrm{x}\right.$ $10^{3} \mathrm{M}^{-1}$ ) in the $3 \mathrm{e}^{-}$reduced state $\mathbf{1} \mathbf{b}^{\mathbf{9}}$ of (tmeda) $\mathrm{Pt}^{2+}$ linked host $\mathbf{1 b}^{\mathbf{1 2 +}}$. Upon reoxidation of the hosts with $\mathrm{Ag}^{+}$, the guests become trapped to provide unprecedented metastable cation-in-cation complexes $\mathbf{C p}^{*}{ }_{2} \mathbf{C o}^{+} @ \mathbf{1} \mathbf{a}^{12+}$ and $\mathbf{C p}_{2} \mathbf{C o}^{+} @ \mathbf{1} \mathbf{b}^{\mathbf{1 2 +}}$ that persist for $>1$ month. Thus, dramatic kinetic effects reveal a way to confine the guests in thermodynamically unfavorable environments. Experimental and DFT studies indicate that $\mathrm{PF}_{6}{ }^{-}$anions kinetically stabilize $\mathbf{C p}_{2}{ }_{2} \mathbf{C o}^{+} @ 1 \mathbf{a}^{12+}$ through electrostatic interactions and by influencing conformational changes of the host that open and close its apertures. However, when $\mathrm{Cp}_{2} \mathrm{Co}^{+} @ 1 \mathbf{a}^{12+}$ was prepared using ferrocenium $\left(\mathrm{Fc}^{+}\right)$instead of $\mathrm{Ag}^{+}$to reoxidize the host, dissociation was accelerated $>200-$ fold even though neither $\mathrm{Fc}^{+}$nor $\mathrm{Fc}$ have any competing affinity for $\mathbf{1 a}^{12+}$. This finding shows that metastable host-guest complexes can respond to subtler stimuli than are required to induce guest release from thermodynamically favorable complexes.
\end{abstract}

The host-guest chemistry ${ }^{1,2}$ of metal-organic nanocages ${ }^{3}$ shows considerable promise for use in molecular sensing, ${ }^{4}$ catalysis, ${ }^{5}$ drug delivery, ${ }^{6}$ and other applications in which it is useful to recognize specific guests, ${ }^{7}$ modify their reactivity, ${ }^{8}$ and/or control their interactions with the bulk environment. ${ }^{9}$ These functions are usually achieved via favorable interactions between guests and the interior of a cage, such as the electrostatic attraction between oppositely charged hosts and guests (Scheme 1, upper left). ${ }^{1}$ This thermodynamically driven behavior has practical implications. For example, cationic guests rarely bind in cationic cages unless other species shield electrostatic repulsion enough to permit affinity between the host and guest (Scheme 1, upper right). ${ }^{10,11}$ Conversely, lowering the charge of a host diminishes its attraction to oppositely charged guests, which has been exploited to induce the rapid, reversible ejection of anions upon reduction of cationic nanocages ${ }^{12 c, g}$ (Scheme 1, bottom). In general, controlling the uptake and release of guests requires the ability to switch on or off the thermodynamic driving force for association, motivating many efforts to dynamically alter host-guest affinity using stimuli (e.g., redox changes, ${ }^{12,13}$ light, ${ }^{14}$ or chemical triggers $\left.{ }^{15-17}\right)^{18}$ that interact with or substantially alter the host or guest.

Herein, we describe cation-in-cation complexes that add to and in some ways challenge the above assumptions. We employed $\mathrm{M}_{6} \mathrm{~L}_{3}$ nanoprisms 1a, $\mathbf{b}^{12+}\left(\mathrm{M}=\right.$ (bipy) $\mathrm{Pt}^{2+}$ for $\mathbf{1 a}^{\mathbf{1 2 +}}$, (tmeda) $\mathrm{Pt}^{2+}$ for $\mathbf{1 b}^{\mathbf{1 2 +}}$; L = (3-py) ${ }_{4}$ porphyrin for both ${ }^{19}$ as redox-active hosts that bind cationic guests decamethylcobaltocenium $\left(\mathrm{Cp}_{2}{ }_{2} \mathrm{Co}^{+}\right)$or cobaltocenium $\left(\mathrm{Cp}_{2} \mathrm{Co}^{+}\right)$
Scheme 1. Influence of Charge on Host-Guest Affinity

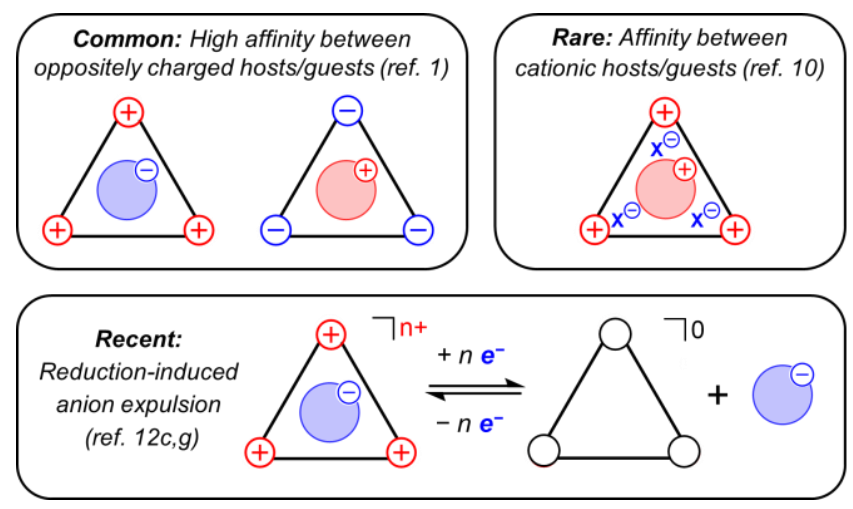

upon reduction ${ }^{20}$ of the walls of the cages (Scheme 2). These findings are, to our knowledge, the first examples of cation uptake induced by the reduction of discrete metal-organic nanocages, ${ }^{21,22}$ which occurs even when the cages retain a positive charge (up to 9+) after reduction. Remarkably, the cationic guests become trapped upon reoxidation of the cages, yielding thermodynamically unfavorable but highly persistent cation-in-cation complexes that take several weeks to fully disassemble. This kinetically controlled ${ }^{23}$ behavior opens new possibilities for containing guests in thermodynamically unfavorable environments and for tuning the rate of guest release with additional stimuli. ${ }^{24}$ Indeed, the rate of guest escape from $\mathbf{C p}^{*}{ }_{2} \mathbf{C o}^{+} @ \mathbf{1} \mathbf{a}^{12+}$ was very sensitive to experimental conditions. The $\mathrm{Cp}^{*}{ }_{2} \mathrm{Co}^{+}$guest disso- 
Scheme 2. Cation Trapping via Redox Cycling

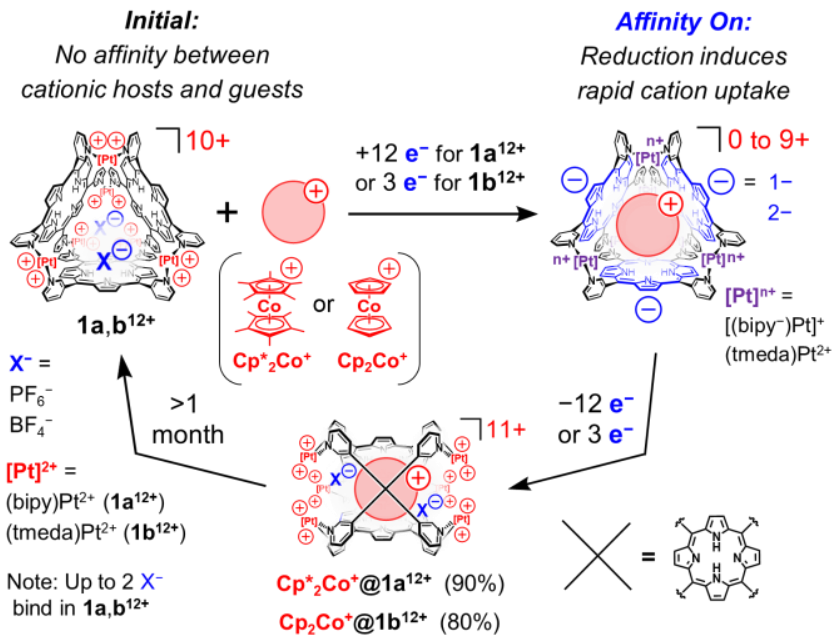

Affinity Off: Highly persistent metastable cation-in-cation complexes

ciates more rapidly in dilute solutions, and its escape was accelerated considerably $(>200 x)$ when the host was reoxidized with ferrocenium $\left(\mathrm{Fc}^{+}\right)$cations rather than $\mathrm{Ag}^{+}$. We expect that these findings will be useful for precisely managing host-guest association in many applications of nanocages.

\section{Results and Discussion.}

Characterization of the cation-in-cation complexes $\mathrm{Cp}_{2}{ }^{*} \mathrm{Co}^{+} @ 1 \mathbf{1}^{12+}$ and $\mathrm{Cp}_{2} \mathrm{Co}^{+} @ 1 \mathbf{b}^{12+}$. The redox-induced trapping of $\mathrm{Cp}^{*}{ }_{2} \mathrm{Co}^{+}$by $\mathbf{1 a}^{12+}$ was evident from experiments in which $\mathbf{1 a}^{12+}$ was reduced with $\mathrm{Cp}^{*}{ }_{2} \mathrm{Co}$ followed by reoxidation. Electrochemical measurements ${ }^{19}$ indicate that this host can accept up to $12 \mathrm{e}^{-}$(two sequential $1 \mathrm{e}^{-}$reductions of each wall and one $1 \mathrm{e}^{-}$reduction of each bipy ligand) at potentials accessible by $\mathrm{Cp}^{*}{ }_{2} \mathrm{Co}^{20}{ }^{20}$ so $1 \mathbf{1 a}^{12+}$ was treated with 12 equiv of $\mathrm{Cp}^{*}{ }_{2} \mathrm{Co}$ in $\mathrm{CD}_{3} \mathrm{CN}$ followed by reoxidation with a slight excess of $\mathrm{AgPF}_{6}$ or $\mathrm{AgBF}_{4}(\mathrm{Eq} 1)$. The ${ }^{1} \mathrm{H}$ NMR spectra

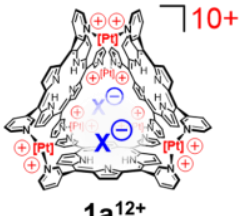

$1 \mathrm{a}^{12+}$

$[\mathrm{Pt}]^{2+}=($ bipy $) \mathrm{Pt}^{2+}$ $\mathrm{X}^{-}=\mathrm{PF}_{6}^{-}, \mathrm{BF}_{4}$

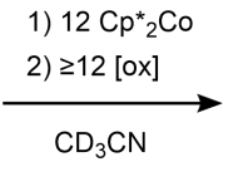

$[\mathrm{ox}]=\mathrm{AgPF}_{6}$ $\mathrm{AgBF}_{4}$

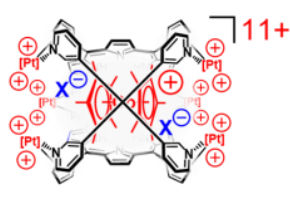

$\mathrm{Cp}_{2}{ }_{2} \mathrm{Co}^{+} @ 1 \mathrm{a}^{12+}$

$(90 \%)$
(Figures 1A, S1, and S4) of the reoxidized solutions showed new resonances accounting for $\sim 90 \%$ of the cage, while the original signals of $\mathbf{1 a}^{12+}$ accounted for $10 \%$. The new signals correspond to $\mathbf{C p}^{*}{ }_{2} \mathbf{C o}^{+} @ \mathbf{1} \mathbf{a}^{12+}$ as evident from an upfield resonance near $-4.9 \mathrm{ppm}$ that integrates as about $30 \mathrm{H}$ for the encapsulated decamethylcobaltocenium guest.

The ${ }^{1} \mathrm{H}$ NMR signals of $\mathbf{C p}{ }_{2} \mathbf{C o}^{+} @ \mathbf{1} \mathbf{a}^{12+}$ were better resolved for $\mathrm{BF}_{4}^{-}$solutions (Figure 1A) while slightly broader signals were observed with $\mathrm{PF}_{6}{ }^{-}$(Figure $\mathrm{S} 4$ ). In both cases, a more upfield signal (ca. $-5.5 \mathrm{ppm}$ ) for the guest appears at low temperatures (Figures 1B, S6). The -0.6 ppm change
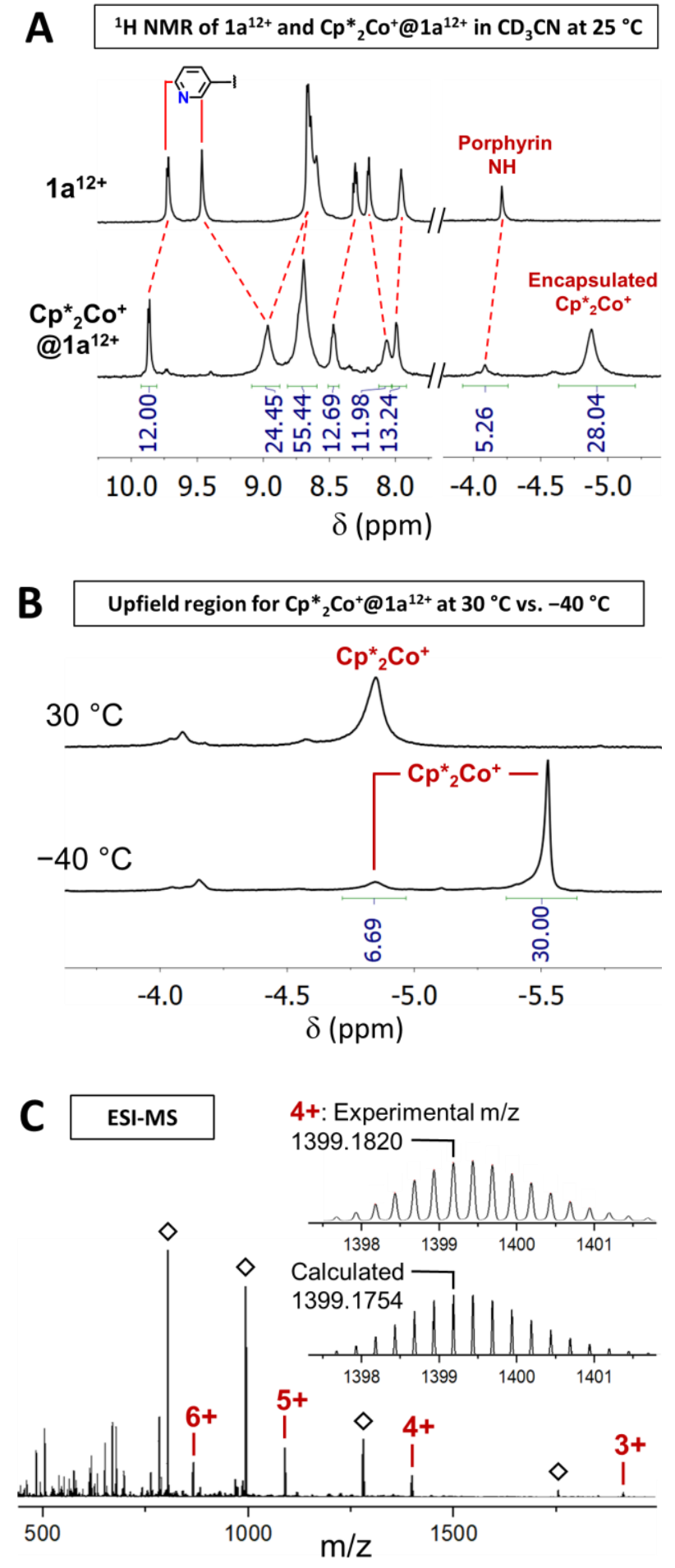

Figure 1. (A) ${ }^{1} \mathrm{H}$ NMR spectra of a $1.2 \mathrm{mM}$ solution of $\mathbf{1 a} \cdot \mathbf{1 2 B F}_{\mathbf{4}}$ in $\mathrm{CD}_{3} \mathrm{CN}$ before and after reduction/reoxidation with 12 equiv Cp* ${ }_{2} \mathrm{Co} / 12.5$ equiv $\mathrm{AgBF}_{4}$ to form $\mathbf{C p}_{2} \mathbf{C o}^{+} @ \mathbf{1 a}^{\mathbf{1 2 +}}$. Changes of the signals of $\mathbf{1 a}^{12+}$ are indicated with dotted lines, and select signals are assigned. (B) Upfield ${ }^{1} \mathrm{H}$ NMR region of $\mathbf{C p}^{*}{ }_{2} \mathbf{C o}^{+} @-$ $\mathbf{1 a}^{12+}\left(\mathrm{BF}_{4}{ }^{-}\right.$anions) in $\mathrm{CD}_{3} \mathrm{CN}$ compared at $30^{\circ} \mathrm{C}$ and $-40^{\circ} \mathrm{C}$ (see Figure S3 for full spectra from -40 to $80^{\circ} \mathrm{C}$ ). (C) ESI(+)-MS spectrum of a solution of $\mathbf{C p}_{2}{ }_{2} \mathbf{C o}^{+} @ 1 \mathbf{a}^{12+}$ generated from 1a•12PF 6 with $\mathrm{Cp}^{*}{ }_{2} \mathrm{Co}$ and $\mathrm{AgPF}_{6}$ in $\mathrm{CD}_{3} \mathrm{CN}$. Peaks labeled 3+ to 6+ refer to $\left[\mathrm{M}-\mathrm{nPF}_{6}\right]^{\mathrm{n}+}$ where $\mathrm{M}=\left[\mathbf{C p}^{*} \mathbf{C o}^{+} @ \mathbf{1 a}^{12+}\right] \cdot 13 \mathrm{PF}_{6}$ and $n=3-6$. Diamonds mark signals arising from the empty host $\mathbf{1 a}^{12+}$. The inset compares experimental and calculated peaks for the $\left[\mathrm{M}-4 \mathrm{PF}_{6}\right]^{4+}$ signal of $\left[\mathbf{C p}^{*} \mathbf{C o}^{+} @ \mathbf{1 a}^{\mathbf{1 2 +}}\right] \cdot 13 \mathrm{PF}_{6}$. 
indicates closer $\mathrm{CH}_{3}---\pi$ contacts that likely result from a tighter conformation of the host. The new signal represents $50 \%$ of the host-guest complex at $-40{ }^{\circ} \mathrm{C}$ for the $\mathrm{PF}_{6}{ }^{-}$salt in $\mathrm{CD}_{3} \mathrm{CN}$ (Figure $\mathrm{S} 6$ ), while $\mathrm{BF}_{4}^{-}$solutions show $>80 \%$ conversion to the new conformation (Figure 1B). The influence of $\mathrm{PF}_{6}{ }^{-}$vs. $\mathrm{BF}_{4}^{-}$on this equilibrium suggests that these anions interact with the host-guest complex. ${ }^{1}$ We have previously established association of two $\mathrm{PF}_{6}{ }^{-}$anions in $\mathbf{1 a}, \mathbf{b}^{12+, 19}$ which should be strengthened by the presence of cationic guests in the cages. Thus, in $\mathrm{PF}_{6}{ }^{-}$solutions, $\mathbf{C p}^{*} \mathbf{C o}^{+} @ \mathbf{1 a}^{12+}$ can be regarded as a mixture of $\left[\left(\mathrm{Cp}_{2}^{*} \mathrm{Co}^{+} \cdot 2 \mathrm{PF}_{6}{ }^{-}\right) @ \mathbf{1 a}^{12+}\right]^{11+}$, $\left[\left(\mathrm{Cp}_{2}{ }_{2} \mathrm{Co}^{+} \cdot \mathrm{PF}_{6}{ }^{-}\right) @ \mathbf{1 a}^{12+}\right]^{12+}$, and $\left[\mathrm{Cp}_{2}{ }_{2} \mathrm{Co}^{+} @ \mathbf{1 a}^{12+}\right]^{13+}$, with the former predominating at typical NMR sample concentrations of $1.2 \mathrm{mM}$ of the cage. ${ }^{25}$ Only a single ${ }^{19} \mathrm{~F}$ NMR signal was observed for the anions at all temperatures (Figure S7), demonstrating that rapid exchange occurs between the anions in bulk solution and those in the cage. This observation shows that different forms of $\mathbf{C p}^{*}{ }_{2} \mathbf{C o}^{+} @ \mathbf{1} \mathbf{a}^{12+}$ observed by ${ }^{1} \mathrm{H}$ NMR spectroscopy do not simply correspond to different numbers of anions associated with the host-guest complex. Different conformations of $\mathbf{C p}^{*}{ }_{2} \mathbf{C o}^{+} @ \mathbf{1} \mathbf{a}^{\mathbf{1 2 +}}$ were evaluated by DFT calculations and are discussed below.

The identity of $\mathbf{C p}^{*}{ }_{2} \mathbf{C o}^{+} @ 1 \mathbf{a}^{12+}$ was confirmed by ESI(+)MS measurements, which showed a series of signals for Cp* ${ }_{2} \mathrm{Co}^{+} @ 1 \mathbf{a}^{12+}$ accompanied by 7 - $10 \mathrm{PF}_{6}{ }^{-}$anions (Figure 1C). Diffusion-ordered ${ }^{1} \mathrm{H}$ NMR spectroscopy (DOSY, Figures S2, S5) also supported the identity of $\mathbf{C p}^{*} \mathbf{C o}^{+} @ \mathbf{1}^{\mathbf{1 2 +}}$. Neither the ESI-MS nor ${ }^{1} \mathrm{H}$ NMR signals of $\mathbf{C p}^{*} \mathbf{C o}^{+} @ \mathbf{1 a}^{\mathbf{1 2 +}}$ were observed for simple mixtures of $\mathrm{Cp}_{2}{ }_{2} \mathrm{Co}^{+}$and $\mathbf{1 a ^ { 1 2 + }}$ in $\mathrm{CD}_{3} \mathrm{CN}$, demonstrating that cation uptake does not occur in the $12+$ charge state of the host. It is rare for charged metalorganic hosts to bind guests of the same charge, ${ }^{10,11}$ and Cp* ${ }_{2} \mathbf{C o}^{+} @ 1 a^{12+}$ is the first example to be formed by cycling an electroactive host to and from a more favorable redox state for binding the charged guest. ${ }^{21}$ The $\mathrm{Cp}_{2}{ }_{2} \mathrm{Co}^{+}$guest slowly escapes the host (see below), further distinguishing Cp* $\mathbf{C o}^{+} @ 1 \mathbf{1 a}^{12+}$ as a thermodynamically unfavorable cation-in-cation complex, ${ }^{26}$ whereas in previously characterized examples, ${ }^{10,11}$ anions or other mediating factors provided affinity between the cationic hosts and guests. Nevertheless, $\mathbf{C p}^{*}{ }_{2} \mathbf{C o}^{+} @ \mathbf{1} \mathbf{a}^{\mathbf{1 2 +}}$ is kinetically very stable and could be dried of solvent, washed with DCM to remove excess $\mathrm{Cp}_{2} \mathrm{Co}^{+}$, and redissolved in $\mathrm{CD}_{3} \mathrm{CN}$ without degradation.

A similar host-guest complex with the smaller $\mathrm{Cp}_{2} \mathrm{Co}^{+}$cation was prepared by treating the (tmeda) $\mathrm{Pt}^{2+}$-linked host $\mathbf{1 b}^{12+}$ with $\geq 3$ equiv of $\mathrm{Cp}_{2} \mathrm{Co}$ in $\mathrm{CD}_{3} \mathrm{CN}$, followed by reoxidation with $\mathrm{AgPF}_{6}$. These conditions provided $\sim 80 \%$ conversion to the cation-in-cation complex $\mathbf{C p}_{2} \mathbf{C o}^{+} @ \mathbf{1} \mathbf{b}^{\mathbf{1 2 +}}$ when carried out at the same concentration of host $(1.2 \mathrm{mM})$ used to prepare $\mathbf{C p}_{2}^{*} \mathbf{C o}^{+} @ \mathbf{1 a}^{12+}$. The bound $\mathrm{Cp}_{2} \mathrm{Co}^{+}$cation in $\mathbf{C p}_{2} \mathbf{C o}^{+} @ 1 b^{12+}$ exhibited a ${ }^{1} \mathrm{H}$ NMR chemical shift $(-2.18$ ppm, Figure 2) that was considerably upfield of that of free $\mathrm{Cp}_{2} \mathrm{Co}^{+}$(5.65 ppm). The identity of $\mathbf{C p}_{2} \mathbf{C o}^{+} @ \mathbf{1} \mathbf{b}^{\mathbf{1 2 +}}$ was confirmed by DOSY NMR and ESI(+)-MS measurements (see Figures S14 and S18). Similar complexes were not observed upon reoxidation of samples of $\mathbf{1 a}^{\mathbf{1 2}+}$ that were reduced with $\mathrm{Cp}_{2} \mathrm{Co}$ (up to 9 equiv) nor after $\mathbf{1} \mathbf{b}^{\mathbf{1 2}+}$ was reduced with Cp* ${ }_{2}$ Co (up to 6 equiv). Reported structures of closely related (bipy) $\mathrm{Pd}^{2+}$ and (tmeda) $\mathrm{Pd}^{2+}$ linked prisms show that the former has a wider cavity, ${ }^{27}$ which may explain the preference for the (bipy) $\mathrm{Pt}^{2+}$ linked cage $\mathbf{1 a}^{12+}$ to trap $\mathrm{Cp}_{2}{ }_{2} \mathrm{Co}^{+}$ while $\mathbf{1 b}^{12+}$ traps the smaller $\mathrm{Cp}_{2} \mathrm{Co}^{+}$cation.

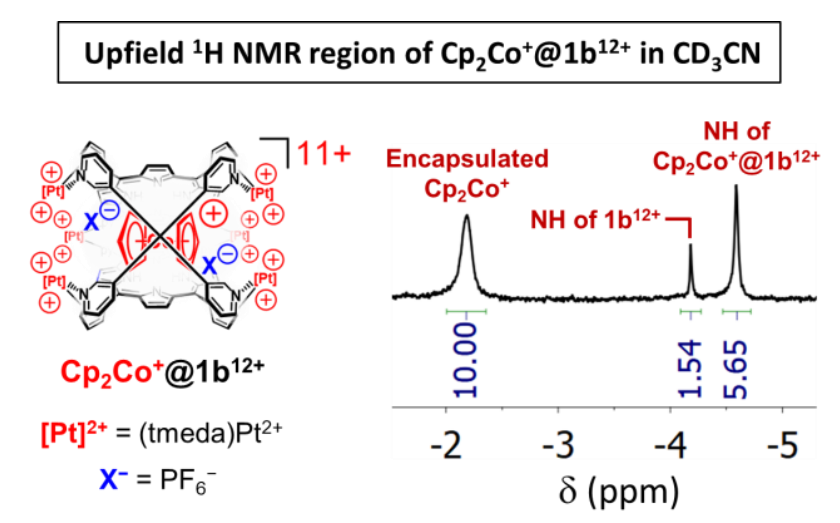

Figure 2. Upfield region of the ${ }^{1} \mathrm{H}$ NMR spectrum of a $1.2 \mathrm{mM}$ solution of $\mathbf{1 b} \cdot \mathbf{1 2} \mathbf{P F}_{6}$ in $\mathrm{CD}_{3} \mathrm{CN}$ after reduction/reoxidation with 3.5 equiv $\mathrm{Cp}_{2} \mathrm{Co}$ and 4 equiv $\mathrm{AgPF}_{6}$ to form $\mathbf{C p}_{2} \mathbf{C o}^{+} @ \mathbf{1 b}^{\mathbf{1 2 +}}$. Comparison of the porphyrin NH signals of remaining of $\mathbf{1 b}^{\mathbf{1 2}+}$ vs. $\mathbf{C p}_{2} \mathbf{C o}^{+} @ \mathbf{1} \mathbf{b}^{12+}$ indicate 79\% conversion to the host-guest complex. See Figure S12 for the full spectrum.

DFT analysis of the structure of $\mathrm{Cp}_{2} * \mathrm{Co}^{+} @ \mathbf{1 b}^{12+}$. Thermodynamic stability is imparted to many cation-in-cation complexes by anions that mediate interactions between the charged host and its cationic guests. ${ }^{10} \mathrm{~A}$ similar effect likely contributes to the kinetic stability of $\mathbf{C p}^{*} \mathbf{C o}^{+} @ 1 \mathbf{a}^{12+}$ and $\mathbf{C p}_{2} \mathbf{C o}^{+} @ \mathbf{1} \mathbf{b}^{12+}$. This possibility is supported by DFT structural optimization of the $\left[\left(\mathrm{Cp}_{2} \mathrm{Co}^{+} \cdot 2 \mathrm{PF}_{6}{ }^{-} @ \mathbf{1 a}^{12+}\right]^{11+}\right.$ form of $\mathbf{C p}_{2} \mathbf{C o}^{+} @ 1 \mathbf{a}^{12+}$ (Figures 3A-D) ${ }^{28}$ starting from the geometry reported for the solid-state structure of a (bipy) $\mathrm{Pd}^{2+}$ linked analogue of $\mathbf{1 a}^{12+}$ that includes two $\mathrm{PF}_{6}{ }^{-}$anions in the cage. ${ }^{27}$ Even before optimization, the anions were spaced well to fit $\mathrm{Cp}^{*}{ }_{2} \mathrm{Co}^{+}$, resulting in minimal change of the $\mathrm{P}---\mathrm{P}$ distance in the cation-in-cation complex ( $D_{\mathrm{P}-\mathrm{P}}=12.1 \AA$, DFT, Figure $3 \mathrm{~B}$ ) relative to the starting structure (Dp-P $=12.3 \AA$, $\mathrm{XRD}$ ). The shortest $\mathrm{C}---\mathrm{F}$ contact between $\mathrm{PF}_{6}{ }^{-}$and $\mathrm{Cp}^{*}{ }_{2} \mathrm{Co}^{+}$ in the optimized structure equals the sum of the van der Waals radii of $\mathrm{C}$ and $\mathrm{F}(3.17 \AA),{ }^{29}$ and the four shortest $\mathrm{C}---\mathrm{F}$ contacts average to a slightly longer distance of $3.33 \AA$ (Figure $3 \mathrm{~B}$ ). Thus, the anions are positioned well in the cage to stabilize the cationic guest.

As can be seen in Figure 3C, the anions restrict the aperture of the host. Since $\mathrm{Cp}^{*}{ }_{2} \mathrm{Co}^{+}$tightly matches the internal width of $\mathbf{1 a}^{\mathbf{1 2 +}}$, at least one anion must be displaced from $\left[\left(\mathrm{Cp}_{2}{ }_{2} \mathrm{Co}^{+} \cdot 2 \mathrm{PF}_{6}{ }^{-}\right) @ \mathbf{1 a}^{12+}\right]^{11+}$ to permit dissociation of the cationic guest. Structures of $\left[\left(\mathrm{Cp}_{2}^{*} \mathrm{Co}^{+} \cdot \mathrm{PF}_{6}{ }^{-}\right) @ \mathbf{1 a}^{12+}\right]^{12+}$ and $\left[\mathrm{Cp}^{*} \mathrm{Co}^{+} @ 1 \mathbf{1}^{12+}\right]^{13+}$ were optimized, in both cases finding that the (bipy) $\mathrm{Pt}^{2+}$ linkers are swung outwards (Figures 3E$\mathrm{G}$ and $\mathrm{S45}$ ) relative to their placement over the openings of the host when two anions are bound (Figures 3A,C). This finding suggests that the anions not only block the apertures but also influence conformational changes of the host that open and close its portals. In the closed form, each $\mathrm{PF}_{6}$ anion engages in two short $(\leq 2.5 \AA) \mathrm{CH}---\mathrm{F}$ interactions with the 3-position $\mathrm{CH}$ bonds of pyridyl groups that span across one edge of a porphyrin wall (Figure 3D). As a result, the $\mathrm{CH}---\mathrm{HC}$ spacings of these pyridyl groups are maintained at $<6 \AA$ in $\left[\left(\mathrm{Cp}_{2}^{*} \mathrm{Co}^{+} \cdot 2 \mathrm{PF}_{6}{ }^{-}\right) @ \mathbf{1 a}^{12+}\right]^{11+}$ and expand by more than $1 \AA$ upon loss of one anion (Figure $3 \mathrm{G}$ ). The remaining anion accommodates this change by shifting to interact with the pyridyl groups of two different porphyrin 

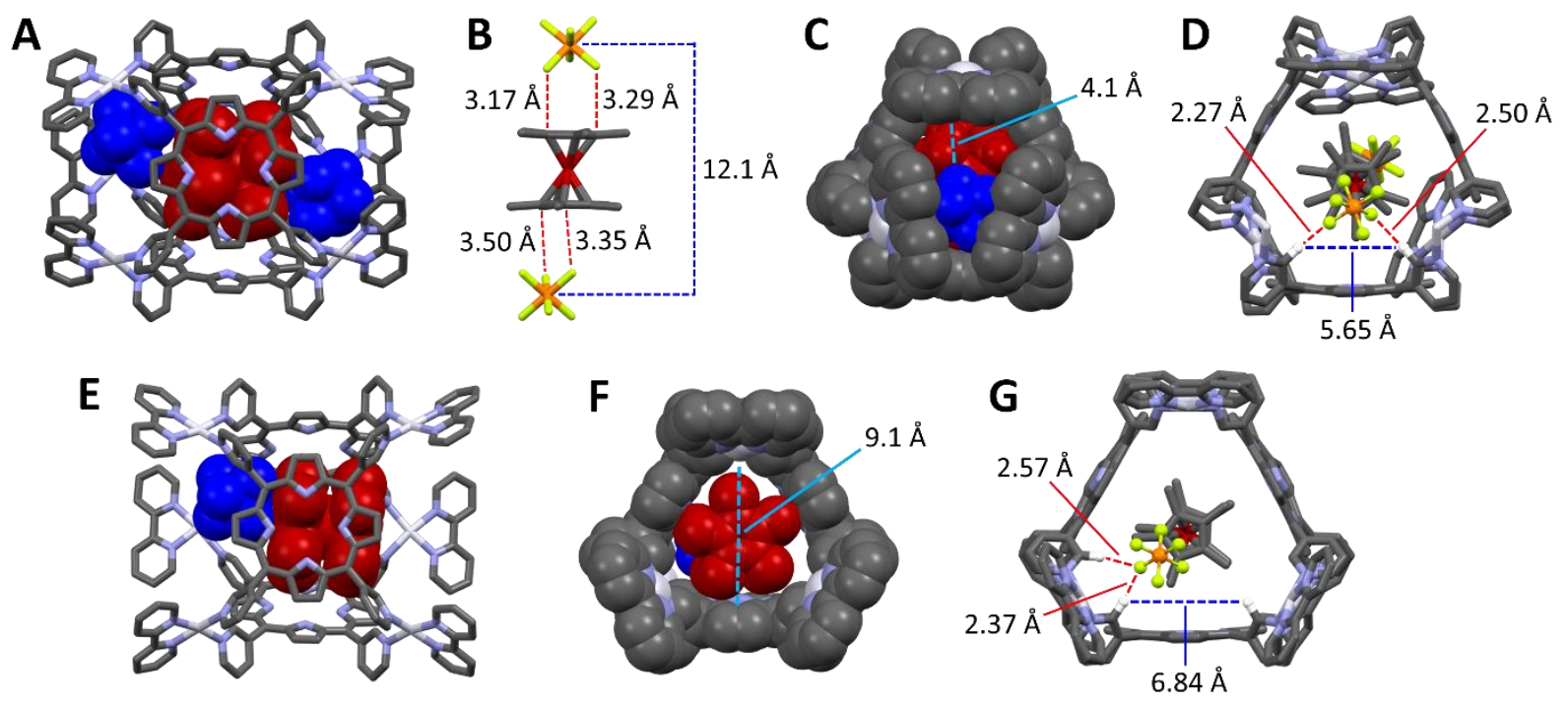

Figure 3. Computationally optimized structures of the $\left[\left(\mathrm{Cp}_{2} \mathrm{Co}^{+} \cdot 2 \mathrm{PF}_{6}{ }^{-}\right) @ \mathbf{1 a}^{12+}\right]^{11+}(\mathrm{A}-\mathrm{D})$ and $\left[\left(\mathrm{Cp}^{*}{ }_{2} \mathrm{Co}^{+} \cdot \mathrm{PF}_{6}\right)^{-} @ \mathbf{1 a}^{12+}\right]^{12+}(\mathrm{E}-$ G) forms of $\mathbf{C p}^{*}{ }_{2} \mathbf{C o}^{+} @ 1 a^{12+}$. Space-filling representations depict the $\mathrm{Cp}^{*}{ }_{2} \mathrm{Co}^{+}$guest in red, $\mathrm{PF}_{6}{ }^{-}$anions in blue, carbon atoms of the host in gray, $\mathrm{N}$ in light blue, and $\mathrm{Pt}$ in white. Stick representations depict carbon in gray, $\mathrm{N}$ in light blue, $\mathrm{F}$ in chartreuse, $\mathrm{P}$ in orange, Co in red, and Pt in white. Only select hydrogens are shown (in white) to illustrate specific $\mathrm{H}---\mathrm{F}$ and $\mathrm{H}---\mathrm{H}$ distances. (A) View facing a porphyrin wall of $\left[\left(\mathrm{Cp}^{*}{ }_{2} \mathrm{Co}^{+} \cdot 2 \mathrm{PF}_{6}{ }^{-}\right) @ \mathbf{1 a}^{12+}\right]^{11+}$. (B) Spacing of the $\mathrm{PF}_{6}{ }^{-}$and $\mathrm{Cp}_{2}{ }_{2} \mathrm{Co}^{+}$guests with the cage omitted for clarity. The P---P distance and four shortest C---F distances are labeled. (C) View of a triangular face of $\left[\left(\mathrm{Cp}_{2}{ }_{2} \mathrm{Co}^{+} \cdot 2 \mathrm{PF}_{6}{ }^{-}\right) @ \mathbf{1 a}^{12+}\right]^{11+}$ with the opening between the van der Waals surfaces of a $\mathrm{PF}_{6}{ }^{-}$anion and bipy ligand labeled. (D) View of the same triangular face with selected $\mathrm{CH}---\mathrm{F}$ and $\mathrm{CH}---\mathrm{HC}$ distances illustrated. Two bipy ligands are omitted for clarity. (E) View facing a porphyrin wall of $\left[\left(\mathrm{Cp}_{2}^{*} \mathrm{Co}^{+} \bullet \mathrm{PF}_{6}\right)^{-} @ \mathbf{1 a}^{12+}\right]^{12+}$. (F) View of a triangular face of $\left[\left(\mathrm{Cp}^{*}{ }_{2} \mathrm{Co}^{+} \bullet \mathrm{PF}^{-}\right) @ \mathbf{1 a}^{12+}\right]{ }^{12+}$ with $^{2}$ the width of the aperture labeled. (G) View of the opposite triangular face with selected $\mathrm{CH}---\mathrm{F}$ and $\mathrm{CH}---\mathrm{HC}$ distances indicated.

walls (Figure 3G). It is presumably the role of the $\mathrm{CH}---\mathrm{F}$ interactions on tuning the $\mathrm{CH}---\mathrm{HC}$ spacing that influences the opening and closing of the apertures of $\mathbf{C p}^{*}{ }_{2} \mathbf{C o}^{+} @ 1 \mathbf{a}^{12+}$.

The open form of the host explains how large guests can enter and exit $\mathbf{1 a}^{\mathbf{1 2 +}}$, while the closed form likely contributes to the kinetic stability of $\mathbf{C} \mathbf{p}_{2} \mathbf{C o}^{+} @ \mathbf{1} \mathbf{a}^{\mathbf{1 2 +}} .{ }^{30}$ It is worth pointing out that switching from the closed to open state also shortens the average centroid-to-centroid distance of the porphyrins by $>2.5 \%$ (Figure S46), consistent with the observation by ${ }^{1} \mathrm{H}$ NMR spectroscopy of conformational changes that produce a more upfield signal of the $\mathrm{Cp}_{2}{ }_{2} \mathrm{Co}^{+}$ guest at reduced temperatures (see Figure $1 \mathrm{~B}$ above). Thus, the lower temperature conformation of $\mathbf{C p}^{*}{ }_{2} \mathbf{C o}^{+} @ \mathbf{1} \mathbf{a}^{\mathbf{1 2 +}}$ is attributed to the opening of the apertures of the host. However, the experimentally observed conformational change does not appear to require anion dissociation since the ratio of the two conformations is not influenced much by concentration (Figures S6 and S8) but is influenced by the identity of the anions $\left(\mathrm{PF}_{6}{ }^{-}\right.$vs. $\mathrm{BF}_{4}^{-}$, Figures $\mathrm{S} 6$ and $1 \mathrm{~B}$, respectively).

Examination of cation-uptake by the reduced hosts. Cation uptake by the reduced states of $\mathbf{1 a}^{\mathbf{1 2 +}}$ and $\mathbf{1} \mathbf{b}^{\mathbf{1 2 +}}$ was probed by quantifying the formation of the cation-in-cation complexes after different times in the reduced states of the hosts, and in the case of $\mathbf{1 a}^{\mathbf{1 2 +}}$, after adding varying equivalents of $\mathrm{Cp}_{2}{ }_{2} \mathrm{Co}$ to access different reduced states. Solutions of $\mathbf{1 a} \cdot \mathbf{1 2} \mathbf{P F}_{\mathbf{6}}\left(1.2 \mathrm{mM}\right.$ in $\mathrm{CD}_{3} \mathrm{CN}$ ) reoxidized 5 min after adding 12 equiv of $\mathrm{Cp}_{2}{ }_{2} \mathrm{Co}$ provided the same conversion to $\mathbf{C p}_{2}{ }_{2} \mathbf{C o}^{+} @ 1 \mathbf{1 a}^{12+}(\sim 90 \%)$ as samples reoxidized after $1 \mathrm{~h}$, indicating that $\mathrm{Cp}_{2}{ }_{2} \mathrm{Co}^{+}$rapidly enters $\mathbf{1 a}^{0}$, reaching equilibrium concentrations of $\mathbf{C p}^{*}{ }_{2} \mathbf{C o}^{+} @ 1 \mathbf{a}^{0}$ within 5 minutes. Thus, the apertures of $\mathbf{1 a}^{\mathbf{0}}$ do not present a major barrier to the passage of $\mathrm{Cp}_{2}{ }_{2} \mathrm{Co}^{+}$, possibly because reduction of the six (bipy) $\mathrm{Pt}^{2+}$ linkers of $\mathbf{1 a}^{\mathbf{1 2 +}}$ lowers charge repulsion between the cationic guest and the portals of the host. Reoxidation of the host after $\leq 1 \mathrm{~min}$ did, however, result in lower conversions to $\mathbf{C p}_{2}{ }_{2} \mathbf{C o}^{+} @ 1 \mathbf{1 a}^{12+}$. A 65 \% yield was observed after $1 \mathrm{~s}$ in the reduced state and slightly less than maximum conversion was attained after $1 \mathrm{~min}$ (see Figure S21).

The cation-in-cation complex $\mathbf{C p}^{*} \mathbf{C o}^{+} @ \mathbf{1 a}^{\mathbf{1 2 +}}$ was also formed upon reoxidation of solutions of $\mathbf{1 a}^{12+}$ that were treated with 3 or 9 equiv of $\mathrm{Cp}_{2}{ }_{2} \mathrm{Co}$ to access respectively the $1 \mathrm{a}^{9+}$ state of the host (each porphyrin reduced by $1 \mathrm{e}^{-}$) or the $\mathbf{1 a}^{3+}$ state (each porphyrin and bipy ligand reduced by $1 \mathrm{e}^{-}$). Low yields (ca. $10 \%$ ) of $\mathbf{C p}^{*}{ }_{2} \mathbf{C o}^{+} @ \mathbf{1 a}^{12+}$ were observed after cycling through the $3 \mathrm{e}^{-}$reduced state $\mathbf{1 a}^{9+}($ Figure S24) with conversion to $\mathbf{C p}^{*}{ }_{\mathbf{2}} \mathbf{C o}^{+} @ \mathbf{1} \mathbf{a}^{\mathbf{1 2 +}}$ differing negligibly for samples reoxidized after $1 \mathrm{~h}$ vs. $4 \mathrm{~h}$. Moderate yields of $\mathbf{C p}^{*}{ }_{2} \mathbf{C o}^{+} @ 1 \mathbf{1 a}^{12+}$ (ca.60\%) were observed after cycling through the $9 \mathrm{e}^{-}$reduced state $\mathbf{1 a}^{3+}$. Entry of $\mathrm{Cp}_{2}{ }_{2} \mathrm{Co}^{+}$ into $1 \mathbf{a}^{3+}$ appears to occur very rapidly, with a $40 \%$ yield of Cp* ${ }_{2} \mathbf{C o}^{+} @ 1 \mathbf{a}^{12+}$ observed for samples reoxidized after $10 \mathrm{~s}$, and nearly maximum conversion obtained after $30 \mathrm{~s}$ (Figure S22). A low yield (ca. 10\%) of $\mathbf{C p}^{*} \mathbf{C o}^{+} @ \mathbf{1 a}^{\mathbf{1 2 +}}$ was also obtained after reduction of $\mathbf{1 a}^{\mathbf{1 2 +}}$ to $\mathbf{1 a}^{3+}$ using excess $\mathrm{Cp}_{2} \mathrm{Co}$ in the presence of 10 equiv of $\mathrm{Cp}^{*}{ }_{2} \mathrm{Co}^{+}$(Figure S23). The reduced yield of $\mathbf{C p}^{*} \mathbf{C o}^{+} @ \mathbf{1} \mathbf{a}^{12+}$ in this experiment suggests that $\mathrm{Cp}_{2} \mathrm{Co}^{+}$may compete with $\mathrm{Cp}_{2}{ }_{2} \mathrm{Co}^{+}$for binding in $\mathbf{1 a}^{3+}$. Presumably the smaller $\mathrm{Cp}_{2} \mathrm{Co}^{+}$cation escapes too quickly from $\mathbf{1 a}^{12+}$ upon reoxidation to observe a trapped cation-incation complex involving this host and guest.

The uptake of $\mathrm{Cp}_{2} \mathrm{Co}^{+}$into $\mathbf{1 b}^{9+}$ was found to occur more slowly than uptake of $\mathrm{Cp}_{2}{ }_{2} \mathrm{Co}^{+}$into $\mathbf{1 a}^{0}$ or $\mathbf{1 \mathbf { a } ^ { 3 + }}$. The complex 
$\mathbf{C p}_{2} \mathbf{C o}^{+} @ \mathbf{1} \mathbf{b}^{\mathbf{1 2 +}}$ was not formed when samples of $\mathbf{1} \mathbf{b}^{\mathbf{1 2 +}}$ were reoxidized $5 \mathrm{~s}$ after reduction with 3.5 equiv of $\mathrm{Cp}_{2} \mathrm{Co}$, and slightly less than maximum conversion was obtained when samples were reoxidized after $5 \mathrm{~min}$ (Figure S25). Notably, when $\mathbf{1 b}^{12+}$ was reduced with $\mathrm{Cp}_{2} \mathrm{Co}$ in the presence of excess $\mathrm{Cp}_{2} \mathrm{Co}^{+}$(18 equiv), a nearly quantitative yield of $\mathbf{C p}_{2} \mathbf{C o}^{+} @ 1 \mathbf{1}^{12+}$ was attained upon reoxidation (Figure S13). This result confirms that formation of the trapped cation-incation complex is controlled by the equilibrium concentration of the reduced complex $\mathbf{C p}_{2} \mathbf{C o}^{+} @ \mathbf{1} \mathbf{b}^{9+}$ present upon reoxidation of the host.

Table 1 displays association constants estimated for the binding of $\mathrm{Cp}_{2}^{*} \mathrm{Co}^{+}$or $\mathrm{Cp}_{2} \mathrm{Co}^{+}$in the reduced hosts based on the best yields of $\mathbf{C p}^{*} \mathbf{C o}^{+} @ \mathbf{1 a}^{\mathbf{1 2 +}}$ and $\mathbf{C p}_{2} \mathbf{C o}^{+} @ \mathbf{1} \mathbf{b}^{12+}$ that were found in the above experiments. Strong association $\left(K_{a}=1.3 \times 10^{3} \mathrm{M}^{-1}\right)$ was found for $\mathbf{C p}^{*}{ }_{2} \mathbf{C o}^{+} @ \mathbf{1} \mathbf{a}^{\mathbf{0}}$, while lower association constants of $1.4 \times 10^{2}$ and $3.5 \times 10^{1} \mathrm{M}^{-1}$ were determined for $\mathbf{C p}^{*} \mathbf{C o}^{+} @ 1 \mathbf{1}^{3+}$ and $\mathbf{C p}^{*} \mathbf{C o}^{+} @ \mathbf{1} \mathbf{a}^{9+}$, respectively. Though these latter complexes are relatively weakly bound, the host-guest affinity is notable since the host retains an overall positive charge. Thus, localized regions of negative charge (i.e., zwitterionic character) appear to be sufficient to drive cation uptake into $\mathbf{1 a}^{3+}$ and $\mathbf{1 a}^{9+}$ to form favorable cation-in-cation complexes. This feature is even more evident for $\mathbf{C p}_{2} \mathbf{C o}^{+} @ \mathbf{1} \mathbf{b}^{\mathbf{9}}$, which exhibits stronger association $\left(K_{a}=1.7 \times 10^{3} \mathrm{M}^{-1}\right)$ than $\mathbf{C p}^{*} \mathbf{C o}^{+} @ 1 \mathbf{1}^{0}$ even though $\mathbf{1 b}^{\mathbf{9}+}$ carries a substantial positive charge. Together, these complexes represent the first examples of cation uptake induced by reduction of metal-organic nanocages, ${ }^{21}$ marking a significant addition to the use of redox stimuli to alter the host-guest affinity of such structures. ${ }^{12,13}$

Table 1. Association Constants for Cationic Guests in Different Reduced States of the Hosts 1a, $b^{n+}$.

\begin{tabular}{|c|c|c|c|c|}
\hline Complex & $\begin{array}{c}\mathbf{C p}^{*} \mathbf{C o}^{+} \\
@ 1 \mathbf{1 a}^{0}\end{array}$ & $\begin{array}{c}\mathrm{Cp}^{*} \mathrm{Co}^{+} \\
@ 1 \mathbf{a}^{3+}\end{array}$ & $\begin{array}{c}\mathrm{Cp}^{*} \mathrm{CO}^{+} \\
\mathrm{C1a}^{9+}\end{array}$ & $\begin{array}{c}\mathrm{Cp}_{2} \mathrm{Co}^{+} \\
\mathrm{C}_{1 b^{9+}}\end{array}$ \\
\hline$K_{a}\left(\mathrm{M}^{-1}\right)^{\mathrm{a}}$ & $1.3 \times 10^{3}$ & $1.4 \times 10^{2}$ & $3.5 \times 10^{1}$ & $1.7 \times 10^{3}$ \\
\hline
\end{tabular}

Table 1. (a) Association constants were determined from the yields of $\mathbf{C p}^{*} \mathbf{C o}^{+} @ \mathbf{1} \mathbf{a}^{12+}$ and $\mathbf{C p}_{2} \mathbf{C o}^{+} @ \mathbf{1} \mathbf{b}^{12+}$ observed after reoxidation of solutions of $\mathbf{1 a}^{12+}$ and $\mathbf{1 b}^{12+}$ reduced with $\mathrm{Cp}^{*}{ }_{2} \mathrm{Co}$ or $\mathrm{Cp}_{2} \mathrm{Co}$, respectively, to access the indicated state of the hosts.

Dissociation of the cation-in-cation complexes. The cationic guests slowly dissociate from $\mathbf{C p}^{*}{ }_{2} \mathbf{C o}^{+} @ 1 \mathbf{a}^{12+}$ and $\mathbf{C p}_{2} \mathbf{C o}^{+} @ 1 \mathbf{b}^{12+}$, with respective half-lives of about 15 days and 5 weeks observed at room temperature in $\mathrm{CD}_{3} \mathrm{CN}$. Owing to the faster dissociation of $\mathbf{C p}^{*}{ }_{2} \mathbf{C o}^{+} @ \mathbf{1} \mathbf{a}^{12+}$ and the easier synthesis of the host $\mathbf{1 a}^{\mathbf{1 2 +}}$ vs. $\mathbf{1 b}^{\mathbf{1 2 +}, 19}$ we chose to examine in detail the escape of $\mathrm{Cp}_{2}{ }_{2} \mathrm{Co}^{+}$from $\mathbf{C p}_{2} \mathbf{C o}^{+} @ 1 \mathbf{a}^{12+}$. The above experimental and computational characterization of $\mathbf{C p}^{*}{ }_{2} \mathbf{C o}^{+} @ \mathbf{1 a}^{\mathbf{1 2 +}}$ suggests two likely pathways for dissociation of $\mathrm{Cp}^{*}{ }_{2} \mathrm{Co}^{+}$(Scheme 3$)$. One anion might dissociate prior to escape of the cationic guest, thus opening the apertures of the host, or the cation and an anion could transit out of the cage together as an ion pair after the aperture opens. The kinetics of guest escape were probed experimentally, indicating that both pathways are plausible but that additional, more complex mechanisms also operate.
Scheme 3. Possible pathways for escape of the cationic guest from $\mathrm{Cp}_{2}{ }_{2} \mathrm{Co}^{+} @ 1 \mathrm{a}^{12+}$

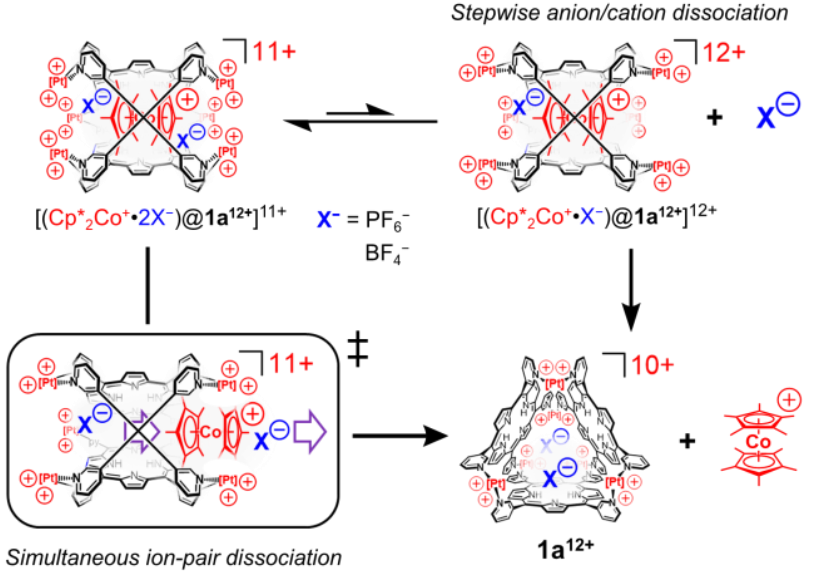

Hexafluorophosphate and tetrafluoroborate solutions of Cp* ${ }_{2} \mathbf{C o}^{+} @ 1 \mathbf{a}^{\mathbf{1 2 +}}$ displayed first-order decay under ordinary conditions $\left(1.2 \mathrm{mM}\right.$ of the host in $\mathrm{CD}_{3} \mathrm{CN}$ reduced with 12 equiv $\mathrm{Cp}^{*}{ }_{2} \mathrm{Co}$ and reoxidized with 12.1 - 12.5 equiv $\mathrm{AgPF}_{6}$ or $\mathrm{AgBF}_{4}$ ). For samples monitored at $23{ }^{\circ} \mathrm{C}$, rate constants of $4.0-10.0 \times 10^{-7} \mathrm{~s}^{-1}$ were found for $\mathrm{PF}_{6}{ }^{-}$solutions and $6.6-$ $15.5 \times 10^{-7} \mathrm{~s}^{-1}$ for $\mathrm{BF}_{4}^{-}$solutions. Though variations of the rate constants were observed, greater consistency was attained for samples prepared at the same time (see Figures S26 and S27). Thus, for subsequent comparisons of specific variables (e.g., temperature, concentration, or different additives), a solution of $\mathbf{C} \mathbf{p}^{*}{ }_{2} \mathbf{C o}^{+} @ \mathbf{1} \mathbf{a}^{12+}$ was prepared for each experiment and split into multiple samples that were then modified as needed.

Eyring analyses $\left(23-80^{\circ} \mathrm{C}\right)$ provided activation parameters of $\Delta H^{\ddagger}=23.9 \pm 2.0 \mathrm{kcal} \mathrm{mol}^{-1}$ and $\Delta S^{\ddagger}=-6.5 \pm 6.2 \mathrm{eu}$ for $\mathrm{PF}_{6}{ }^{-}$solutions of $\mathbf{C p}^{*}{ }_{2} \mathbf{C o}^{+} @ 1 \mathbf{a}^{12+}$ (Figure S29). $\mathrm{BF}_{4}{ }^{-}$solutions displayed similar parameters of $\Delta H^{\ddagger}=22.6 \pm 2.4 \mathrm{kcal}$ $\mathrm{mol}^{-1}$ and $\Delta S^{\ddagger}=-10.5 \pm 7.5$ eu (Figure S31). The large enthalpies of activation can be attributed to electrostatic repulsion of $\mathrm{Cp}_{2} \mathrm{Co}^{+}$passing through the $6+$ charged apertures of $1 \mathbf{a}^{12+} .31$ To interpret the entropies of activation, the entropies associated with conformational changes of the host-guest complex and with anion binding were evaluated. An entropy of $\Delta S=-13.4 \pm 1.9$ eu was determined for conversion of $\mathbf{C p}^{*} \mathbf{C o}^{+} @ \mathbf{1 a}^{\mathbf{1 2 +}}$ to its low-temperature conformation (Figure S42), which appears to be the open form of the host with both $\mathrm{PF}_{6}{ }^{-}$anions associated (see above). For evaluating the entropy of $\mathrm{PF}_{6}-$ binding, the free host $\mathbf{1 a}^{12+}$ was used, rather than $\mathbf{C p}_{2}{ }_{2} \mathbf{C o}^{+} @ \mathbf{1 a}^{12+}$, to permit measurements over a wider temperature range. Changes of the ${ }^{19} \mathrm{~F}$ NMR signals of the anions upon dilution of $\mathbf{1} \mathbf{a} \cdot \mathbf{1 2} \mathbf{P} \mathbf{F}_{\mathbf{6}}$ from 3 to $0.03 \mathrm{mM}$ were measured from -40 to $80{ }^{\circ} \mathrm{C}$ in $\mathrm{CD}_{3} \mathrm{CN}$, allowing association constants and the entropy of anion association $(\Delta S \approx+17 \mathrm{eu})$ to be estimated. ${ }^{32}$ Since anion dissociation and the opening of the portals of $\mathbf{C p}^{*} \mathbf{C o}^{+} @ \mathbf{1 a}^{\mathbf{1 2 +}}$ without anion dissociation both exhibit unfavorable entropies, neither mechanism in Scheme 3 can be ruled out by the negative entropy of activation for guest escape.

Samples of $\mathbf{C p}^{*}{ }_{2} \mathbf{C o}^{+} @ \mathbf{1 a}^{\mathbf{1 2 +}}$ exhibited faster dissociation at higher dilutions $(1.2 \mathrm{mM}$ to $0.075 \mathrm{mM}$, corresponding to $28.8 \mathrm{mM}$ to $1.8 \mathrm{mM} \mathrm{PF}_{6}{ }^{-}$or $\mathrm{BF}_{4}{ }^{-}$, Figures S38 and S40). Since lower concentrations should favor equilibration of 
$\left[\left(\mathrm{Cp}^{*}{ }_{2} \mathrm{Co}^{+} \cdot 2 \mathrm{X}^{-}\right) @ 1 \mathbf{a}^{12+}\right]^{11+}$ to $\left[\left(\mathrm{Cp}_{2}{ }_{2} \mathrm{Co}^{+} \cdot \mathrm{X}^{-}\right) @ 1 \mathbf{a}^{12+}\right]^{12+}$, the increased rates support the stepwise mechanism of Scheme 3 . However, the observed rates did not show a consistent proportionality to the concentration. For example, dilution from $1.2 \mathrm{mM}$ to $0.3 \mathrm{mM}$ resulted in less than 2.5 -fold acceleration for both $\mathrm{PF}_{6}{ }^{-}$and $\mathrm{BF}_{4}^{-}$solutions, while the rate increased to a greater extent upon further dilution (Figures S38 and S40). It is conceivable that ion-pair escape occurs at higher concentrations, while the stepwise mechanism operates at lower concentrations that favor a preequilibrium anion dissociation step. However, additional observations cannot be explained solely using the mechanisms in Scheme 3. Diluted samples sometimes failed to adhere to the welldefined first order kinetics observed for $1.2 \mathrm{mM}$ samples (Figure S38B). Furthermore, addition of a large excess of $\mathrm{TBAPF}_{6}$ (28.8 mM) to $\mathbf{C p}^{*}{ }_{2} \mathbf{C o}^{+} @ \mathbf{1} \mathbf{a}^{12+}$ resulted in negligible inhibition of guest escape for $1.2 \mathrm{mM}$ samples of the hostguest complex (Figure S37), and more dilute samples $(0.3$ $\mathrm{mM}$ and $0.075 \mathrm{mM}$ ) showed at most 2-fold inhibition (Figure S39). Together, these contradictory and inconsistent observations suggest that release of $\mathrm{Cp}_{2}{ }_{2} \mathrm{Co}^{+}$must be subject to more complex influences than suggested by either pathway in Scheme 3.

The sensitivity of the dissociation of $\mathbf{C p}^{*} \mathbf{C o}^{+} @ \mathbf{1} \mathbf{a}^{12+}$ to unexpected factors was most evident from substantial acceleration of this process when the cation-in-cation complex was generated using $\mathrm{Fc}^{+}$as the oxidant instead of $\mathrm{Ag}^{+}$. Nearly complete decay could be observed after $5 \mathrm{~h}$ when samples were reoxidized with $[\mathrm{Fc}] \mathrm{PF}_{6}$ (Figure 4). Rate constants as high as $9.5 \times 10^{-5} \mathrm{~s}^{-1}$ were quantified under these conditions (Figure S41), representing more than a 200 -fold increase from the lowest rates observed using $\mathrm{AgPF}_{6}$ as the

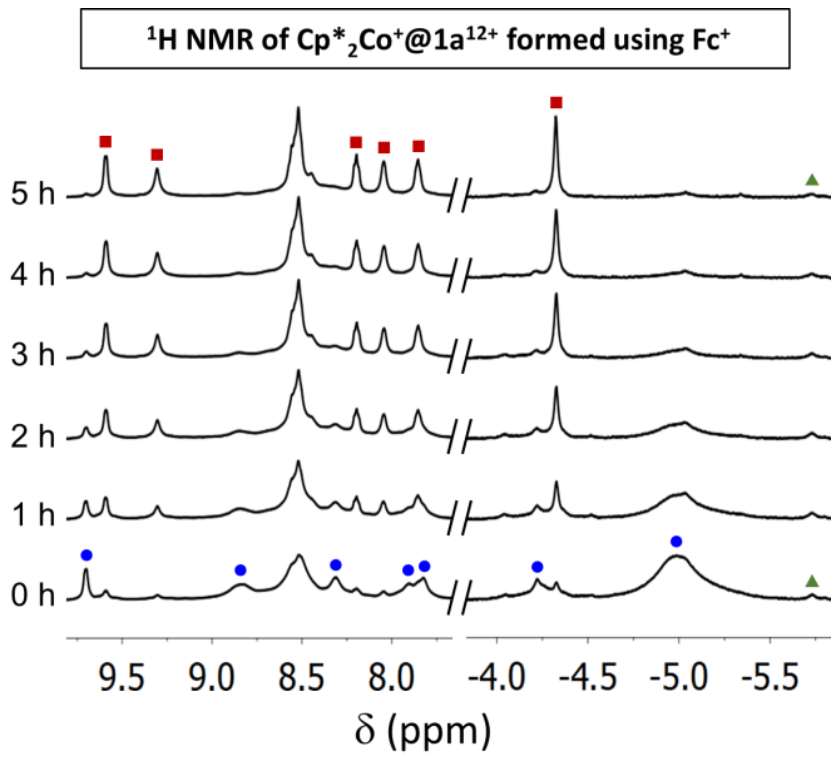

Figure 4. ${ }^{1} \mathrm{H}$ NMR spectra of a solution of $\mathbf{C p}^{*} \mathbf{C o}^{+} @ \mathbf{1 a}^{12+}$ in $\mathrm{CD}_{3} \mathrm{CN}$ that was generated by reduction of $\mathbf{1 a} \cdot \mathbf{1 2} \mathbf{P F}_{6}$ with 12 equiv of $\mathrm{Cp}_{2}{ }_{2} \mathrm{Co}$ followed by reoxidation with 12.5 equiv of $[\mathrm{Fc}] \mathrm{PF}_{6}$. The sample was monitored for $5 \mathrm{~h}$ after oxidation. Signals of the host-guest complex are marked with blue circles in the initial spectrum, and signals of $\mathbf{1 a}^{\mathbf{1 2 +}}$ are marked with red squares in the final spectrum. A green triangle marks an additional signal that showed only a slight decrease over $5 \mathrm{~h}$. oxidant. Since $\mathrm{Fc}$ is formed upon reducing $\mathrm{Fc}^{+}$, it seemed possible that either $\mathrm{Fc}$ or remaining $\mathrm{Fc}^{+}$promotes escape of $\mathrm{Cp}_{2}{ }_{2} \mathrm{Co}^{+}$. To distinguish which species is responsible, samples of $\mathbf{C p}^{*}{ }_{2} \mathbf{C o}^{+} @ \mathbf{1 a}^{12+}$ prepared using AgPF 6 were treated with 5 equiv of $\mathrm{Fc}$ or $[\mathrm{Fc}] \mathrm{PF}_{6}$ relative to the host. Both additives were observed to accelerate the dissociation of the host-guest complex by 5 - 10x (see Figures S32), providing rates that remained much lower than observed for samples of $\mathbf{C p}^{*}{ }_{2} \mathbf{C o}^{+} @ 1 \mathbf{a}^{12+}$ generated directly with $\mathrm{Fc}^{+}$. Additionally, the effects of $\mathrm{Fc}$ and $\mathrm{Fc}^{+}$were inconsistent. Ferrocene failed to accelerate dissociation in one experiment (Figure S33B), and an induction period of $>16 \mathrm{~h}$ was seen in one instance before the influence of $\mathrm{Fc}^{+}$was evident (see Figures S33C).

The inconsistent effects of $\mathrm{Fc}$ and $\mathrm{Fc}^{+}$on promoting dissociation of the host-guest complex suggest a complex mechanism underlying the influence of these additives. One complicating factor is that $\mathrm{Ag}^{0}$ nanoparticles, which were not removed effectively by a $0.2 \mu \mathrm{m}$ filter, reduce most of the added $\mathrm{Fc}^{+}$, while added ferrocene is oxidized slightly by excess $\mathrm{Ag}^{+} .^{33}$ It was considered that $\mathrm{Ag}^{+}$or $\mathrm{Ag}^{0}$ might stabilize the host-guest complex such that reduction or oxidation of these species could be responsible for accelerating the escape of $\mathrm{Cp}_{2}{ }_{2} \mathrm{Co}^{+}$. However, addition of a 24 equiv excess of $\mathrm{AgPF}_{6}$ to samples did not alter the rate of guest-escape from $\mathbf{C p}^{*}{ }_{2} \mathbf{C o}^{+} @ 1 \mathbf{a}^{12+}$ relative to samples oxidized with just a slight excess of $\mathrm{AgPF}_{6}$ (Figure S37). Additionally, the ${ }^{1} \mathrm{H}$ NMR signals of $\mathbf{C p}^{*} \mathbf{C o}^{+} @ \mathbf{1} \mathbf{a}^{\mathbf{1 2 +}}$ were very similar between samples prepared using $\mathrm{AgPF}_{6}$ vs. [Fc]PF 6 (Figure S11), which is implausible if $\mathrm{Ag}^{0}$ nanoparticles or $\mathrm{Ag}^{+}$interact strongly enough with the host-guest complex to stabilize it. Lastly, since $\mathrm{Fc}^{+}$and $\mathrm{Fc}$ have opposite effects on the $\mathrm{Ag}^{+} / \mathrm{Ag}^{0}$ ratio, it does not make sense that both additives could accelerate dissociation of the host-guest complex by altering the amount of $\mathrm{Ag}^{+}$or $\mathrm{Ag}^{0}$ in the sample.

A clear mechanistic picture ultimately could not be elucidated for the influence of $\mathrm{Fc}^{+}$and $\mathrm{Fc}$ on the dissociation of $\mathbf{C p}_{2}{ }_{2} \mathbf{C o}^{+} @ 1 \mathbf{a}^{12+}$. The induction periods and lack of effect observed in some experiments suggest that neither species directly influences dissociation. Instead, decomposition products of $\mathrm{Fc}^{+}$may be responsible. ${ }^{34,35}$ This possibility is supported by observation of a new upfield ${ }^{1} \mathrm{H}$ NMR resonance at $-5.64 \mathrm{ppm}$ in samples with $\mathrm{Fc}^{+}$added (Figures 4 and S10C) as either the sole oxidant or after generating $\mathbf{C p}_{2}{ }_{2} \mathbf{C o}^{+} @ 1 \mathbf{a}^{12+}$ using $\mathrm{AgPF}_{6}$. This signal does not maintain a consistent ratio with those of the host-guest complex, in some cases disappearing faster or slower, suggesting it does not correspond directly to an intermediate in the escape of $\mathrm{Cp}_{2}{ }_{2} \mathrm{Co}^{+}$. However, the new resonance clearly shows that new species are present in solution that do not correspond directly to ferrocene or ferrocenium, neither of which appear to interact strongly with $\mathbf{1 a}^{12+}$ or $\mathbf{C p}^{*}{ }_{2} \mathrm{Co}^{+} @ 1 \mathbf{a}^{12+}$.

From the above investigations, both mechanisms of Scheme 3 remain plausible for the escape of $\mathrm{Cp}_{2}{ }_{2} \mathrm{Co}^{+}$from $\mathrm{Cp}^{*} \mathrm{Co}^{+} @ 1 \mathbf{1}^{12+}$, but the inconsistent kinetics of dissociation make it difficult to draw specific conclusions. It is apparent that more complicated pathways are also available, revealing an interesting feature of the metastable cation-in-cation complex $\mathbf{C p}_{\mathbf{2}} \mathbf{C o}^{+} @ \mathbf{1 a}^{\mathbf{1 2 +}}$-the rate of guest escape can be altered considerably ( $>200$-fold) by subtle factors, including species that do not appear to interact strongly with ei- 
ther the host-guest complex or the free host. Such a situation is not possible for typical, thermodynamically favorable host-guest complexes. In ordinary systems, guest uptake or exchange can be slowed by species that interact strongly with the portals of the host, ${ }^{24}$ and guest ejection can be stimulated by other guests that bind more strongly. ${ }^{12 c-f, 17 b, 18 a}$ It is only because the binding of $\mathrm{Cp}_{2}{ }_{2} \mathrm{Co}^{+}$in $\mathbf{1 a ^ { 1 2 + }}$ is thermodynamically unfavorable that ejection of the guest can be stimulated by species that do not interact strongly with the ground state of the host or host-guest complex. Instead, it is only necessary to stabilize intermediates or transition states to accelerate guest escape. Full elucidation of this behavior will require considerably more investigation, which is beyond the scope of the present study.

\section{Summary and Conclusions.}

In summary, we report redox-driven host-guest chemistry that shows three notable features: (1) Reduction of hosts $\mathbf{1 a}, \mathbf{b}^{12+}$ induces uptake of $\mathrm{Cp}^{*}{ }_{2} \mathrm{Co}^{+}$or $\mathrm{Cp}_{2} \mathrm{Co}^{+}$, representing the first reduction-induced uptake of cations into metalorganic nanocages; (2) The guests become trapped upon reoxidation of the hosts, leading to thermodynamically unfavorably but highly persistent cation-in-cation complexes $\mathbf{C p}_{2}{ }_{2} \mathbf{C o}^{+} @ 1 \mathbf{a}^{12+}$ and $\mathbf{C p}_{2} \mathbf{C o}^{+} @ \mathbf{1 b}^{12+}$; and (3) The rate of guest dissociation from $\mathbf{C p}_{2}{ }_{2} \mathbf{C o}^{+} @ \mathbf{1} \mathbf{a}^{12+}$ shows considerable variation ( $>200$-fold) in response to the oxidant used to prepare this complex.

The redox-induced uptake of cations by $\mathbf{1 a}, \mathbf{b}^{\mathbf{1 2 +}}$ expands the limited range of redox-switchable host-guest chemistry reported for metal-organic hosts. ${ }^{12,13}$ Reduction-induced ejection of anions has greater precedent,12c,12g perhaps because metal-organic nanocages are often positively charged. The high affinity of reduced hosts $\mathbf{1 a}^{\mathbf{0}}$ and $\mathbf{1 b}^{\mathbf{9}+}$ for cations reveals that localized negative charge is sufficient to drive cation-uptake into neutral and cationic hosts. Redoxinduced insertion of cations into extended porous materials is an important process in many contexts (e.g., batteries, electroctalysis), ${ }^{36}$ and we envision that $\mathbf{1 a}, \mathbf{b}^{\mathbf{1 2}+}$ will be useful as discrete porous structures that model this behavior.

The trapping of the cationic guests upon reoxidation of the hosts is another notable finding. Cation-in-cation complexes are very rare, and these new examples are the first to be stabilized by kinetic factors rather than via mediating effects that provide thermodynamic affinity between the cationic host and guest. These findings are relevant to several potential applications of metal-organic nanocages. For example, electrostatic effects greatly influence reactivity inside charged hosts, ${ }^{5 a-c, 8 a, 9 a}$ so the ability to confine organometallic complexes ${ }^{5 \text { f-h }}$ in electrostatically unusual environments may lead to new reactivity. Additionally, the sensitivity of the metastable cation-in-cation complexes to specific conditions could be useful for sensing and drug delivery, though a more detailed mechanistic understanding of this behavior must first be developed.

\section{ASSOCIATED CONTENT}

Supporting Information. Experimental procedures. NMR spectra $\left({ }^{1} \mathrm{H},{ }^{19} \mathrm{~F}\right.$, DOSY, variable temperature). ESI(+)-MS spectra. Details of DFT calculations and .xyz files of calculated structures. These materials are available free of charge via the Internet.

\section{AUTHOR INFORMATION}

\section{Corresponding Author}

*ml1353@chem.rutgers.edu

\section{Author Contributions}

All authors have given approval to the final version of the manuscript.

Notes

The authors declare no competing financial interests.

\section{ACKNOWLEDGMENT}

The authors acknowledge Rutgers, The State University of New Jersey for generous financial support of this research. We acknowledge the Office of Advanced Research Computing (OARC) at Rutgers, The State University of New Jersey for providing access to the Caliburn cluster and associated research computing resources that have contributed to the results reported here.

\section{REFERENCES}

(1) One of the most common recognition motifs for charged metal-organic hosts is the binding of oppositely charged guests: (a) Parac, T. N.; Caulder, D. L.; Raymond, K. N. Selective Encapsulation of Aqueous Cationic Guests into a Supramolecular Tetrahedral $\left[\mathrm{M}_{4} \mathrm{~L}_{6}\right]^{12-}$ Anionic Host. J. Am. Chem. Soc. 1998, 120, 8003-8004. DOI: 10.1021/ja981690y. (b) Sgarlata, C.; Mugridge, J. S.; Pluth, M. D.; Tiedemann, B. E. F.; Zito, V.; Arena, G.; Raymond, K. N. External and Internal Guest Binding of a Highly Charged Supramolecular Host in Water: Deconvoluting the Very Different Thermodynamics. J. Am. Chem. Soc. 2010, 132, 1005-1009. DOI: 10.1021/ja9056739. (c) Rizzuto, F. J.; Wu, W. Y.; Ronson, T. K.; Nitschke, J. R. Peripheral Templation Generates an $\mathrm{M}_{6} \mathrm{~L}_{4}$ Guest-Binding Capsule. Angew. Chem. Int. Ed. 2016, 55, 7958-7962. DOI: 10.1002/anie.201602135. (d) Zhang, D.; Ronson, T. K.; Mosquera, J.; Martinez, A.; Guy, L.; Nitschke, J. R. Anion Binding in Water Drives Structural Adaptation in an Azaphosphatrane-Functionalized

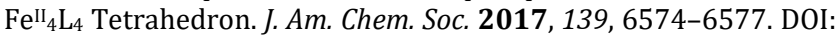
10.1021/jacs.7b02950. (e) Yang, D.; Greenfield, J. L.; Ronson, T. K.;

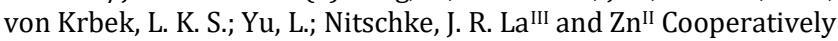
Template a Metal-Organic Capsule. J. Am. Chem. Soc. 2020, 142, 19856-19861. DOI: 10.1021/jacs.0c09991. (f) Preston, D.; Lewis, J. E. M.; Crowley, J. D. Multicavity $\left[\mathrm{Pd}_{\mathrm{n}} \mathrm{L}_{4}\right]^{2 \mathrm{n}}$ Cages with Controlled Segregated Binding of Different Guests. J. Am. Chem. Soc. 2017, 139, 2379-2386. DOI: 10.1021/jacs.6b11982. (g) Vasdev, R. A. S.; Findlay, J. A.; Turner, D. R.; Crowley, J. D. Self-Assembly of a Redox Active, Metallosupramolecular $\left[\mathrm{Pd}_{3} \mathrm{~L}_{6}\right]^{6+}$ Complex Using a Rotationally Flexible Ferrocene Ligand. Chem. Asian J. 2021, 16, 39-43. DOI: 10.1002/asia.202001277. (h) Kim, T. Y.; Digal, L.; Gardiner, M. G.; Lucas, N. T.; Crowley, J. D. Octahedral $\left[\mathrm{Pd}_{6} \mathrm{~L}_{8}\right]^{12+}$ Metallosupramolecular Cages: Synthesis, Structures and Guest-Encapsulation Studies. Chem. Eur. J. 2017, 23, 15089-15097. DOI: 10.1002/chem.201702518. (i) Freye, S.; Michel, R.; Stalke, D.; Pawliczek, M.; Frauendorf, H.; Clever, G. H. Template Control over Dimerization and Guest Selectivity of Interpenetrated Coordination Cages. J. Am. Chem. Soc. 2013, 135, 8476-8479. DOI: 10.1021/ja403184a. (j) Wise, M. D.; Holstein, J. J.; Pattison, P.; Besnard, C.; Solari, E.; Scopelliti, R.; Bricogne, G.; Severin, K. Large, Heterometallic Coordination Cages Based on Ditopic MetalloLigands with 3-pyridyl Donor Groups. Chem. Sci. 2015, 6, 10041010. DOI: $10.1039 / \mathrm{c} 4 \mathrm{sc} 03046 \mathrm{j}$

(2) Other common guests include peptides, aromatics, and metal complexes: (a) Tashiro, S.; Tomínaga, M.; Kawano, M.; Therrien, B.; Ozeki, T.; Fujita, M. Sequence-Selective Recognition of Pep- 
tides within the Single Binding Pocket of a Self-Assembled Coordination Cage. J. Am. Chem. Soc. 2005, 127, 4546-4547. DOI: 10.1021/ja044782y. (b) Roy, B.; Ghosh, A. K.; Srivastava, S.; D’Silva, P.; Mukherjee, P. S. A Pd8 Tetrafacial Molecular Barrel as Carrier for Water Insoluble Fluorophore. J. Am. Chem. Soc. 2015, 137, 1191611919. DOI: 10.1021/jacs.5b08008. (c) Mahata, K.; Frischmann, P. D.; Würthner, F. Giant Electroactive $\mathrm{M}_{4} \mathrm{~L}_{6}$ Tetrahedral Host Self-Assembled with Fe(II) Vertices and Perylene Bisimide Dye Edges. J. Am. Chem. Soc. 2013, 135, 15656-15661. DOI: 10.1021/ja4083039. (d) Leenders, S. H. A. M.; Becker, R.; Kumpulainen, T.; de Bruin, B.; Sawada, T.; Kato, T.; Fujita, M.; Reek, J. N. H. Selective Co-Encapsulation Inside an $\mathrm{M}_{6} \mathrm{~L}_{4}$ Cage. Chem. Eur. J. 2016, 22, 15468-15474. DOI: 10.1002/chem.201603017.

(3) For recent reviews of metal-organic nanocages: (a) Yoshizawa, M.; Klosterman, J. K.; Fujita, M. Functional Molecular Flasks: New Properties and Reactions within Discrete, Self-Assembled Hosts. Angew. Chem. Int. Edit. 2009, 48, 3418-3438. DOI: 10.1002/anie.200805340. (b) Cook, T. R.; Stang, P. J. Recent Developments in the Preparation and Chemistry of Metallacycles and Metallacages via Coordination. Chem. Rev. 2015, 115, 7001-7045. DOI: 10.1021/cr5005666. (c) Brown, C. J.; Toste, F. D.; Bergman, R. G.; Raymond, K. N. Supramolecular Catalysis in Metal-Ligand Cluster Hosts. Chem. Rev. 2015, 115, 3012-3035. DOI: 10.1021/cr4001226. (d) Clever, G. H.; Punt, P. Cation-Anion Arrangement Patterns in Self-Assembled $\mathrm{Pd}_{2} \mathrm{~L}_{4}$ and $\mathrm{Pd}_{4} \mathrm{~L}_{8}$ Coordination Cages. Acc. Chem. Res. 2017, 50, 2233-2243. DOI: 10.1021/acs.accounts.7b00231. (e) Percástegui, E. G.; Ronson, T. K.; Nitschke, J. R. Design and Applications of Water-Soluble Coordination Cages. Chem. Rev. 2020, 120, 13480-13544. DOI: 10.1021/acs.chemrev.0c00672.

(4) For examples of metal-organic nanocages employed as chemical sensors: (a) Chen, L. J.; Ren, Y. Y.; Wu, N. W.; Sun, B.; Ma, J. Q.; Zhang, L.; Tan, H.; Liu, M.; Li, X.; Yang, H. B. Hierarchical SelfAssembly of Discrete Organoplatinum(II) Metallacycles with Polysaccharide via Electrostatic Interactions and Their Application for Heparin Detection. J. Am. Chem. Soc. 2015, 137, 11725-11735. DOI: 10.1021/jacs.5b06565. (b) Chowdhury, A.; Howlader, P.; Mukherjee, P. S. Aggregation-Induced Emission of Platinum(II) Metallacycles and Their Ability to Detect Nitroaromatics. Chem. Eur. J. 2016, 22, 7468-7478. DOI: 10.1002/chem.201600698.

(5) For examples of metal-organic nanocages acting as catalysts or encapsulating transition metal catalysts: (a) Pluth, M. D.; Bergman, R. G.; Raymond, K. N. Supramolecular Catalysis of Orthoformate Hydrolysis in Basic Solution: An Enzyme-like Mechanism. J. Am. Chem. Soc. 2008, 130, 11423-11429. DOI: 10.1021/ja802839v. (b) Hong, C. M.; Morimoto, M.; Kapustin, E. A.; Alzakhem, N.; Bergman, R. G.; Raymond, K. N.; Toste, F. D. Deconvoluting the Role of Charge in a Supramolecular Catalyst. J. Am. Chem. Soc. 2018, 140, 6591-6595. DOI: 10.1021/jacs.8b01701. (c) Cullen, W; Metherell, A. J.; Wragg, A. B.; Taylor, C. G. P.; Williams, N. H.; Ward, M. D. Catalysis in a Cationic Coordination Cage Using a Cavity-Bound Guest and Surface-Bound Anions: Inhibition, Activation, and Autocatalysis. J. Am. Chem. Soc. 2018, 140, 2821-2828. DOI: 10.1021/jacs.7b11334. (d) Bhat, I. A.; Devaraj, A.; Howlader, P.; Chi, K. W.; Mukherjee, P. S. Preparation of a Chiral Pt $\mathrm{t}_{12}$ Tetrahedral Cage and Its Use in Catalytic Michael Addition Reaction. Chem. Comm. 2018, 54, 4814-4817. DOI: 10.1039/c8cc01487f. (e) Murase, T.; Nishijima, Y.; Fujita, M. Cage-Catalyzed Knoevenagel Condensation under Neutral Conditions in Water. J. Am. Chem. Soc. 2012, 134, 162-164. DOI: 10.1021/ja210068f. (f) Bender, T. A.; Bergman, R. G.; Raymond, K. N.; Toste, F. D. A Supramolecular Strategy for Selective Catalytic Hydrogenation Independent of Remote Chain Length. J. Am. Chem. Soc. 2019, 141, 11806-11810. DOI: 10.1021/jacs.9b05604. (g) García-Simón, C.; Gramage-Doria, R.; Raoufmoghaddam, S.; Parella, T.; Costas, M.; Ribas, X.; Reek, J. N. H. Enantioselective Hydroformylation by a Rh-Catalyst Entrapped in a Supramolecular Metallocage. J. Am. Chem. Soc. 2015, 137, 26802687. DOI: 10.1021/ja512637k. (h) Wang, Q. Q.; Gonell, S.; Leenders, S. H. A. M.; Dürr, M.; Ivanovic-Burmazovic, I.; Reek, J. N.
H. Self-Assembled Nanospheres with Multiple Endohedral Binding Sites Pre-Organize Catalysts and Substrates for Highly Efficient Reactions. Nature Chemistry 2016, 8, 225-230. DOI: $10.1038 /$ nchem. 2425 .

(6) For examples of binding and release of drug molecules from metal-organic hosts: (a) Cullen, W.; Turega, S.; Hunter, C. A.; Ward, M. D. pH-Dependent Binding of Guests in the Cavity of a Polyhedral Coordination Cage: Reversible Uptake and Release of Drug Molecules. Chem. Sci. 2015, 6, 625 - 631. DOI: 10.1039/C4SC02090A. (b) Lewis, J. E. M.; Gavey, E. L.; Cameron, S. A.; Crowley, J. D. Stimuli-Responsive $\mathrm{Pd}_{2} \mathrm{~L}_{4}$ Metallosupramolecular Cages: Towards Targeted Cisplatin Drug Delivery. Chem. Sci. 2012, 3, 778 - 784. DOI: 10.1039/C2SC00899H. (c) Rizzuto, F. J.; Carpenter, J. P.; Nitschke, J. R. Multisite Binding of Drugs and Natural Products in an Entropically Favorable, Heteroleptic Receptor. J. Am. Chem. Soc. 2019, 141, 9087 - 9095. DOI: 10.1021/jacs.9b03776

(7) For examples of selective guest recognition or separation by metal-organic nanocages: (a) Zhang, D.; Ronson, T. K.; Lavendomme, R.; Nitschke, J. R. Selective Separation of Polyaromatic Hydrocarbons by Phase Transfer of Coordination Cages. Journal of the American Chemical Society 2019, 141, 18949-18953. DOI: 10.1021/jacs.9b10741. (b) Ganta, S.; Chand, D. K. Multi-Stimuli-Responsive Metallogel Molded from a $\mathrm{Pd}_{2} \mathrm{~L}_{4}$-Type Coordination Cage: Selective Removal of Anionic Dyes. Inorg. Chem. 2018, 57, 36343645. DOI: 10.1021/acs.inorgchem.7b02239. (c) Mochizuki, M.; Inoue, T.; Yamanishi, K.; Koike, S.; Kondo, M.; Zhang, L.; Aoki, H. Efficient Removal of Perchlorate Ion from Water by a Water-Insoluble $\mathrm{M}_{2} \mathrm{~L}_{4}$ Type Compound. Dalton Trans. 2014, 43, 17924-17927. DOI: 10.1039/c4dt02900c. (d) Howlader, P.; Zangrando, E.; Mukherjee, P. S. Self-Assembly of Enantiopure $\mathrm{Pd}_{12}$ Tetrahedral Homochiral Nanocages with Tetrazole Linkers and Chiral Recognition. J. Am. Chem. Soc. 2020, 142, 9070-9078. DOI: 10.1021/jacs.0c03551.

(8) For examples of nanocages modifying the pKa or other reactivity of guests: (a) Pluth, M. D.; Bergman, R. G.; Raymond, K. N. Making Amines Strong Bases: Thermodynamic Stabilization of Protonated Guests in a Highly-Charged Supramolecular Host. J. Am. Chem. Soc. 2007, 129, 11459-11467. DOI: 10.1021/ja072654e. (b) Takezawa, H.; Shitozawa, K.; Fujita, M. Enhanced Reactivity of Twisted Amides inside a Molecular Cage. Nat. Chem. 2020, 12, 574578. DOI: 10.1038/s41557-020-0455-y.

(9) For examples of nanocages stabilizing guests by preventing reactivity that would occur in the bulk environment: (a) Dong, V. M.; Fiedler, D.; Carl, B.; Bergman, R. G.; Raymond, K. N. Molecular Recognition and Stabilization of Iminium Ions in Water. J. Am. Chem. Soc. 2006, 128, 14464-14465. DOI: 10.1021/ja0657915. (b) Mal, P.; Breiner, B.; Rissanen, K.; Nitschke, J. R. White Phosphorus Is Air-Stable Within a Self-Assembled Tetrahedral Capsule. Science 2009, 324, 1697-1699. DOI: 10.1126/science.1175313. (c) Bairagya, M. das; Bujol, R. J.; Elgrishi, N. Fighting Deactivation: Classical and Emerging Strategies for Efficient Stabilization of Molecular Electrocatalysts. Chem. Eur. J. 2020, 26, 3991-4000. DOI: 10.1002/CHEM.201904499.

(10) Most examples of cation-in-cation complexes are stabilized by anions that screen the electrostatic repulsion between the cationic hosts and guests: (a) Bourgeois, J. P.; Fujita, M.; Kawano, M.; Sakamoto, S.; Yamaguchi, K. A Cationic Guest in a $24^{+}$Cationic Host. J. Am. Chem. Soc. 2003, 125, 9260-9261. DOI: 10.1021/ja0349002. (b) Bruns, C. J.; Fujita, D.; Hoshino, M.; Sato, S.; Stoddart, J. F.; Fujita, M. Emergent Ion-Gated Binding of Cationic Host-Guest Complexes within Cationic $\mathrm{M}_{12} \mathrm{~L}_{24}$ Molecular Flasks. J. Am. Chem. Soc. 2014, 136, 12027-12034. DOI: 10.1021/ja505296e. (c) Takezawa, H.; Tabuchi, R.; Sunohara, H.; Fujita, M. Confinement of Water-Soluble Cationic Substrates in a Cationic Molecular Cage by Capping the Portals with Tripodal Anions. J. Am. Chem. Soc. 2020, 142, 17919-17922. DOI: 10.1021/jacs.0c08835. (d) Clever, G. H.; Kawamura, W.; Tashiro, S.; Shiro, M.; Shionoya, M. Stacked Platinum Complexes of the Magnus' Salt Type inside a Coordination Cage. Angew. Chem. Int. Ed. 2012, 51, 2606-2609. DOI: 10.1002/anie.201108197. (e) Li, Y. H.; Zhang, Y.; Legrand, Y. M.; 
van der Lee, A.; Jiang, J. J.; Chen, C. X.; Su, C. Y.; Barboiu, M. Hydrophobic Metallo-supramolecular $\mathrm{Pd}_{2} \mathrm{~L}_{4}$ Cages for Zwitterionic Guest Encapsulation in Organic Solvents. Dalton Trans. 2017, 46, 1520415207. DOI: $10.1039 / \mathrm{c} 7 \mathrm{dt03517a}$.

(11) There are limited examples in which other noncovalent interactions overcome electrostatic repulsion to promote affinity between cationic guests and cationic hosts: (a) Yoshizawa, M.; Kumazawa, K.; Fujita, M. Room-Temperature and Solution-State Observation of the Mixed-Valence Cation Radical Dimer of Tetrathiafulvalene, [(TTF $\left.)_{2}\right]^{+}$, within a Self-Assembled Cage. J. Am. Chem. Soc. 2005, 127, 13456-13457. DOI: 10.1021/ja053508g. (b) Zhang, D.; Ronson, T. K.; Greenfield, J. L.; Brotin, T.; Berthault, P.; Leónce, E.; Zhu, J. L.; Xu, L.; Nitschke, J. R. Enantiopure [Cs+ ${ }^{+} / \mathrm{Xe} C$ Cryptophane] $\subset \mathrm{Fe}^{\mathrm{Il}} \mathrm{L}_{4} \mathrm{H}_{4}$ Hierarchical Superstructures. J. Am. Chem. Soc. 2020, 141, 8339-8345. DOI: 10.1021/jacs.9b02866. (c) Vellé, A.; Cebollada, A.; Iglesias, M.; Sanz Miguel, P. J. Argentophilicity as Essential Driving Force for a Dynamic Cation-Cation Host-Guest System: $\left[\mathrm{Ag}(\text { Acetonitrile })_{2}\right]+\subset\left[\mathrm{Ag}_{2}(\text { Bis-NHC })_{2}\right]^{2+}(\mathrm{NHC}=\mathrm{N}-$ Heterocyclic Carbene). Inorg. Chem. 2014, 53, 10654-10659. DOI: 10.1021/ic501715h. (d) Trabolis, A.; Khashab, N.; Fahrenbach, A. C.; Friedman, D. C.; Colvin, M. T.; Cotí, K. K.; Benítez, D.; Tkatchouk, E.; Olsen, J.-C.; Belowich, M. E.; Carmielli, R.; Khatib, H. A.; Goddard III, W. A.; Wasielewski, M. R.; Stoddart, J. F. Radically Enhanced Molecular Recognition Nat. Chem. 2010, 2, 42 - 49. DOI: 10.1038/nchem.479. (e) Kaseborn, M.; Holstein, J. J.; Clever, G. H.; Lutzen, A. A Rotaxane-like Cage-in-Ring Structural Motif for a Metallosupramlecular $\mathrm{Pd}_{6} \mathrm{~L}_{12}$ Aggregate. Angew. Chem. Int. Ed. 2018, 57, 12171 - 12175. DOI: 10.1002/anie.201806814

(12) For examples of redox-switchable host-guest chemistry involving metal-organic nanocages: (a) Sun, W. Y.; Kusukawa, T.; Fujita, M. Electrochemically Driven Clathration/Declathration of Ferrocene and Its Derivatives by a Nanometer-Sized Coordination Cage. J. Am. Chem. Soc. 2002, 124, 11570-11571. DOI: 10.1021/ja0206285. (b) Croué, V.; Goeb, S.; Szalóki, G.; Allain, M.; Sallé, M. Reversible Guest Uptake/Release by Redox-Controlled Assembly/Disassembly of a Coordination Cage. Angew. Chem. Int. Ed. 2015, 55, 1746-1750. DOI: 10.1002/anie.201509265. (c) Szalóki, G.; Croué, V.; Carré, V.; Aubriet, F.; Alévêque, O.; Levillain, E.; Allain, M.; Aragó, J.; Ortí, E.; Goeb, S.; Sallé, M. Controlling the Host-Guest Interaction Mode through a Redox Stimulus. Angew. Chem. Int. Ed. 2017, 56, 16272-16276. DOI: 10.1002/anie.201709483. (d) Colomban, C.; Szalóki, G.; Magalia, ]; Gómez, L.; Goeb, S.; Sallé, M.; Costas, M.; Ibas, X. \& Host-Guest Systems Reversible $\mathrm{C}_{60}$ Ejection From a Metallocage through the Redox-Dependent Binding of a Competitive Guest. Chem. Eur. J. 2017, 23, 3016-3022. DOI 10.1002/chem.201700273. (e) Krykun, S.; Dekhtiarenko, M.; Canevet, D.; Carré, V.; Aubriet, F.; Levillain, E.; Allain, M.; Voitenko, Z.; Sallé, M.; Goeb, S. Metalla-Assembled Electron-Rich Tweezers: Redox-Controlled Guest Release Through Supramolecular Dimerization. Angew. Chemie. Int. Ed. 2019, 59, 716-720. DOI: 10.1002/anie.201912016. (f) Dekhtiarenko, M.; Krykun, S.; Carré, V.; Aubriet, F.; Canevet, D.; Allain, M.; Voitenko, Z.; Sallé, M.; Goeb, $\mathrm{S}$. Tuning the structure and the properties of dithiafulvene metallaassembled tweezers. Org. Chem. Front. 2020, 7, 2040-2046. DOI: 10.1039/d0qo00641f. (g) Lu, Z.; Ronson, T. K.; Nitschke, J. R. Reversible Reduction Drives Anion Ejection and $\mathrm{C}_{60}$ Binding within an $\mathrm{Fe}^{\mathrm{II}} \mathrm{L}_{6}$ Cage. Chem. Sci. 2020, 11, 1097-1101. DOI: 10.1039/c9sc05728e. (h) Plajer, A. J.; Rizzuto, F. J.; von Krbek, L. K. S.; Gisbert, Y.; Martínez-Agramunt, V.; Nitschke, J. R. Oxidation Triggers Guest Dissociation during Reorganization of an $\mathrm{Fe}^{\mathrm{II}} 4 \mathrm{~L}_{6}$ Twisted Parallelogram. Chem. Sci. 2020, 11, 10399-10404. DOI: 10.1039/d0sc04352d.

(13) For reviews of redox-active metal-organic nanostructures: (a) Croué, V.; Goeb, S.; Sallé, M. Metal-driven self-assembly: the case of redox-active discrete architectures. Chem. Comm. 2015, 51, 7275-7289. DOI: 10.1039/c5cc00597c. (b) Goeb, S.; Sallé, M. Electron-Rich Coordination Receptors Based on Tetrathiafulvalene Derivatives: Controlling the Host-Guest Binding. Acc. Chem. Res. 2021, 54, 1043-1055. DOI: 10.1021/acs.accounts.0c00828. (c)
Winter, R. F. The molecular electrochemistry of metal-organic metallamacrocycles. Curr. Opin. Electrochem. 2018, 8, 14-23. DOI: 10.1016/j.coelec.2017.11.011.

(14) For examples of photoswitchable host-guest chemistry involving metal-organic nanocages: (a) Murase, T.; Sato, S.; Fujita, M. Switching the Interior Hydrophobicity of a Self-Assembled Spherical Complex through the Photoisomerization of Confined Azobenzene Chromophores. Angew. Chem. Int. Ed. 2007, 46, 51335136. DOI: 10.1002/anie.200700793. (b) Clever, G. H.; Tashiro, S.; Shionoya, M. Light-Triggered Crystallization of a Molecular HostGuest Complex. J. Am. Chem. Soc. 2010, 132, 9973-9975. DOI: 10.1021/ja103620z. (c) Han, M.; Michel, R.; He, B.; Chen, Y.-S.; Stalke, D.; John, M.; Clever, G. H.; Han, M.; Michel, R.; He, B.; Stalke, D.; John, M.; Clever, G. H.; Chen, Y. Light-Triggered Guest Uptake and Release by a Photochromic Coordination Cage. Angew. Chem. Int. Ed. 2013, 52, 1319-1323. DOI: 10.1002/anie.201207373. (d) Kishi, N.; Akita, M.; Kamiya, M.; Hayashi, S.; Hsu, H.-F.; Michito, Y Facile Catch and Release of Fullerenes Using Using a Photoresponsive Molecular Tube. J. Am. Chem. Soc. 2013, 135, 12976 - 12979. DOI: $10.1021 /$ ja406893y

(15) For examples of pH switchable host-guest chemistry involving metal-organic nanocages: (a) Nakabayashi, K.; Kawano, M.; Fujita, M. pH-Switchable Through-Space Interaction of Organic Radicals within a Self-Assembled Coordination Cage. Angew. Chem Int. Ed. 2005, 44, 5322-5325. DOI: 10.1002/anie.200501568. (b) Clever, G. H.; Shionoya, M. A pH Switchable Pseudorotaxane Based on a Metal Cage and a Bis-Anionic Thread. Chem. Eur. J. 2010, 16, 11792-11796. DOI: 10.1002/chem.201002013. (c) Smulders, M. M. J.; Zarra, S.; Nitschke, J. R. Quantitative Understanding of Guest Binding Enables the Design of Complex Host-Guest Behavior. J. Am Chem. Soc. 2013, 135, 7039-7046. DOI: 10.1021/ja402084x. (d) Chan, A. K. W.; Lam, W. H.; Tanaka, Y.; Wong, K. M. C.; Yam, V. W. W. Multiaddressable Molecular Rectangles with Reversible HostGuest Interactions: Modulation of $\mathrm{pH}$-controlled Guest Release and Capture. Proc. Natl. Acad. Sci. U.S.A. 2015, 112, 690-695. DOI: 10.1073/pnas.1423709112.

(16) For an example of switchable host-guest chemistry triggered by covalent reactivity: Omoto, K.; Tashiro, S.; Shionoya, M. Phase-Dependent Reactivity and Host-Guest Behaviors of a Metallo-Macrocycle in Liquid and Solid-State Photosensitized Oxygenation Reactions. J. Am. Chem Soc. 2021, 143, 5406-5412. DOI: 10.1021/jacs.0c13338.

(17) For examples of switchable host-guest chemistry triggered by competing or complementary guests: (a) Löffler, S.; Lübben, J.; Krause, L.; Stalke, D.; Dittrich, B.; Clever, G. H. Triggered Exchange of Anionic for Neutral Guests inside a Cationic Coordination Cage. J. Am. Chem. Soc. 2015, 137, 1060-1063. DOI: 10.1021/ja5130379. (b) Samanta, S. K.; Schmittel, M. Guest Encapsulation and Coronene- $\mathrm{C}_{60}$ Exchange in Supramolecular Zinc Porphyrin Tweezers, Grids and Prisms. Org. Biomol. Chem. 2013, 11, 3108-3115. DOI: 10.1039/c3ob27481k.

(18) For examples of multi-stimuli-responsive host-guest chemistry involving metal-organic nanocages: (a) Castilla, A. M.; Ronson, T. K.; Nitschke, J. R. Sequence-Dependent Guest Release Triggered by Orthogonal Chemical Signals. J. Am. Chem. Soc. 2016, 138, 2342-2351. DOI: 10.1021/jacs.5b13016. (b) Samanta, S. K.; Quigley, J.; Vinciguerra, B.; Briken, V.; Isaacs, L. Cucurbit[7] uril Enables Multi-Stimuli-Responsive Release from the Self-Assembled Hydrophobic Phase of a Metal Organic Polyhedron. J. Am. Chem. Soc. 2017, 139, 9066-9074. DOI: 10.1021/jacs.7b05154. (c) Li, R. J.; Tessarolo, J.; Lee, H.; Clever, G. H. Multi-Stimuli Control over Assembly and Guest Binding in Metallo-Supramolecular Hosts Based on Dithienylethene Photoswitches. J. Am. Chem. Soc. 2021, 143, 3865-3873. DOI: 10.1021/jacs.0c12188. (d) Lisboa, L. S.; Findlay, J. A.; Wright, L. J.; Hartinger, C. G.; Crowley, J. D. A Reduced-Symmetry Heterobimetallic [PdPtL 4$]^{4+}$ Cage: Assembly, Guest Binding, and Stimulus-Induced Switching. Angew. Chem. Int. Ed. 2020, 59, 11101-11107. DOI: 10.1002/anie.202003220. 
(19) Dutton, K. G.; Rothschild, D. A.; Pastore, D. B.; Emge, T. J.; Lipke, M. C. The Influence of Redox-Active Linkers on the Stability and Physical Properties of a Highly Electroactive Porphyrin Nanoprism. Inorg. Chem. 2020, 59, 12616-12624. DOI: 10.1021/acs.inorgchem.0c01719

(20) Connelly, N. G.; Geiger, W. E. Chemical Redox Agents for Organometallic Chemistry. Chem. Rev. 1996, 96, 877-910. DOI: $10.1021 / \mathrm{cr} 940053 \mathrm{x}$

(21) We claim the first examples of reduction-induced cation uptake by metal-organic nanocages based on a survey of the literature that included examining all papers cited by or citing the review articles in references $13 \mathrm{a}-\mathrm{c}$ and the original research reports in references 12a-h. There are, however, examples of soluble inorganic clusters that uptake cations when reduced (see ref. 22).

(22) Mitsumoto, K.; Nishikawa, H.; Newton, G. N.; Oshio, H. Encapsulation Controlled Single Molecule Magnestism in Tetrathiafulvalene-Capped Cyanide-Bridged Cubes. Dalton. Trans. 2012, 41, 13601 - 13608. DOI: 10.1039/C2DT30908D

(23) For reviews discussing the kinetics of host-guest exchange processes: (a) Pluth, M. D.; Raymond, K. N. Reversible Guest Exchange Mechanisms in Supramolecular Host-Guest Assemblies. Chem. Soc. Rev. 2007, 36, 161-171. DOI: 10.1039/B603168B. (b) Rieth, S.; Hermann, K.; Wang, B. Y.; Badjić, J. D. Controlling the dynamics of molecular encapsulation and gating. Chem. Soc. Rev. 2011, 40, 1609-1622. DOI: 10.1039/c005254j. (c) Akine, S.; Sakata, Y. Control of Guest Binding Kinetics in Macrocycles and Molecular Cages. Chem. Lett. 2020, 49, 428-441. DOI: $10.1246 / \mathrm{cl} .200017$.

(24) For examples of tuning host-guest exchange rates: (a) Davis, A. V; Fiedler, D.; Seeber, G.; Zahl, A.; van Eldik, R.; Raymond, K. N. Guest Exchange Dynamics in an $\mathrm{M}_{4} \mathrm{~L}_{6}$ Tetrahedral Host. J. Am. Chem. Soc. 2006, 128, 1324-1333. DOI: 10.1021/ja056556. (b) Zarra, S.; Smulders, M. M. J.; Lefebvre, Q.; Clegg, J. K.; Nitschke, J. R. Guanidinium Binding Modulates Guest Exchange within an $\left[\mathrm{M}_{4} \mathrm{~L}_{6}\right]$ Capsule. Angew. Chem. Int. Ed. 2012, 51, 6882-6885. DOI: 10.1002/anie.201202665. (c) von Krbek, L. K. S.; Roberts, D. A.; Pilgrim, B. S.; Schalley, C. A.; Nitschke, J. R. Multivalent Crown Ether Receptors Enable Allosteric Regulation of Anion Exchange in an $\mathrm{Fe}_{4} \mathrm{~L} 6$ Tetrahedron. Angew. Chem. Int. Ed. 2018, 57, 14121-14124. DOI: 10.1002/anie.201808534. (d) Sakata, Y.; Murata, C.; Akine, S. Anion-Capped Metallohost Allows Extremely Slow Guest Uptake and on-Demand Acceleration of Guest Exchange. Nat. Commun. 2017, 8, 1-7. DOI: 10.1038/ncomms16005. (e) Akine, S.; Miyashita, M.; Nabeshima, T. A Metallo-molecular Cage That Can Close the Apertures with Coordination Bonds. J. Am. Chem. Soc. 2017, 139, 4631-4634. DOI: 10.1021/jacs.7b00840.

(25) The ${ }^{19} \mathrm{~F}$ NMR chemical shift of $\mathrm{PF}_{6}{ }^{-}$anions differed substantially $(>0.25 \mathrm{ppm})$ in solutions of $\sim 1 \mathrm{mM} \mathrm{1a^{12+ }}$ (Figure S43) or Cp* ${ }_{2} \mathbf{C o}^{+} @ 1 a^{12+}$ (Figure S9) relative to that observed for solutions of $\mathrm{TBAPF}_{6}$ in $\mathrm{CD}_{3} \mathrm{CN}$, indicating that $\mathrm{PF}_{6}$ - associates strongly with the free host and the cation-in-cation complex. 25-fold dilution of $\mathbf{1 a}^{12+}$ and $\mathbf{C p}^{*}{ }_{2} \mathbf{C o}^{+} @ 1 \mathbf{a}^{12+}$ caused the ${ }^{19} \mathrm{~F}$ NMR resonance to shift about halfway towards the signal observed for $\mathrm{TBAPF}_{6}$, which shows no concentration dependence. These observations suggest $\mathbf{1 a}^{12+}$ and $\mathbf{C p}^{*}{ }_{2} \mathbf{C o}^{+} @ 1 \mathbf{1}^{12+}$ maintain significant, though decreased, association with $\mathrm{PF}_{6}{ }^{-}$even at very low concentrations.

(26) We claim that $\mathbf{C p}_{2}{ }_{2} \mathbf{C o}^{+} @ 1 \mathbf{a}^{12+}$ and $\mathbf{C p}_{2} \mathbf{C o}^{+} @ 1 \mathbf{b}^{12+}$ are the first well-characterized metastable cation-in-cation complexes based on a survey of the literature that included examining all papers cited by or citing the research reports in references 10 and 11. Fujita has reported UV-vis spectroelectrochemistry results that may indicate a metastable complex of $\left[\mathrm{TTF}^{+}\right]_{2}$ bound in a metalorganic host, but the short-lived complex $(<2 \mathrm{~h})$ was not further characterized to confirm this possibility (see reference 11a).

(27) Bar, A. K.; Mohapatra, S.; Zangrando, E.; Mukherjee, P. S. A Series of Trifacial $\mathrm{Pd}_{6}$ Molecular Barrels with Porphyrin Walls. Chem. - Eur. J. 2012, 18, 9571- 9579. DOI: 10.1002/chem.201201077.
(28) Only $\mathbf{C p}_{2}{ }_{2} \mathbf{C o}^{+} @ 1 \mathbf{a}^{12+}$ was examined computationally because the tight fit of the $\mathrm{Cp}^{*}{ }_{2} \mathrm{Co}^{+}$guest in $\mathbf{1 \mathbf { a } ^ { 1 2 + }}$ allowed efficient convergence of structural optimization, while of $\mathbf{C p}_{2} \mathbf{C o}^{+} @ 1 \mathbf{b}^{12+}$ failed to converge in a reasonable timeframe, likely because $\mathrm{Cp}_{2} \mathrm{Co}^{+}$ has greater conformational freedom in $\mathbf{1 b}^{\mathbf{1 2 +}}$. Details of DFT calculations are provided in Section 8 of the supporting information.

(29) Mantina, M.; Chamberlin, A. C.; Valero, R.; Cramer, C. J.; Truhlar, D. G. Consistent van der Waals Radii for the Whole Main Group. J. Phys. Chem. A 2009, 113, 5806-5812. DOI: 10.1021/jp8111556.

(30) Similar conformational changes are known to influence the kinetics of guest association/dissociation in a variety of hosts: (a) Davis, A. V.; Raymond, K. N. The Big Squeeze: Guest Exchange in an $\mathrm{M}_{4} \mathrm{~L}_{6}$ Supramolecular Host. J. Am. Chem. Soc. 2005, 127, 79127919. DOI: 10.1021/ja051037s. (b) Rieth, S.; Bao, X.; Wang, B.-Y.; Hadad, C. M.; Badjić, J. D. Gated Molecular Recognition and Dynamic Discrimination of Guests. J. Am. Chem. Soc. 2010, 132, 773-776. DOI: $10.1021 /$ ja908436c.

(31) Hmadeh, M.; Fahrenbach, A. C.; Basu, S.; Trabolsi, A.; Benítez, D.; Li, H.; Albrecht-Gary, A.-M.; Elhabiri, M.; Stoddart, J. F. Electrostatic Barriers in Rotaxanes and Pseudorotaxanes. Chem. Eur. J. 2011, 17, 6076-6087. DOI: 10.1002/CHEM.201002933

(32) Association of $\mathrm{PF}_{6}$ - in $\mathbf{1 a}^{\mathbf{1 2 +}}$ was analyzed on the assumption of two independent binding sites per host, providing $K_{\mathrm{a}}$ of about $1-2 \times 10^{3} \mathrm{M}^{-1}$ over the temperature range of -40 to $80^{\circ} \mathrm{C}$. As described in the SI, these results are of limited reliability due to assumptions made to simplify analysis, but as shown in Table S1, concentration-dependent relative changes of the ${ }^{19} \mathrm{~F}$ NMR chemical shifts of the anions are very similar across all temperatures, suggesting the strength of anion binding is not affected strongly by temperature. This low temperature-dependence indicates low enthalpic contributions, showing that binding of anions in $\mathbf{1 a}^{\mathbf{1 2 +}}$ must be driven by a relatively large favorable entropy of association.

(33) $\mathrm{The} \mathrm{Fc}^{+} / \mathrm{Fc}$ and $\mathrm{Ag}^{+} / \mathrm{Ag}$ redox couples have very similar potentials in MeCN. See reference 20.

(34) (a) Singh, A.; Chowdhury, D. R.; Paul, A. A kinetic study of ferrocenium cation decomposition utilizing an integrated electrochemical methodology composed of cyclic voltammetry and amperometry. Analyst 2014, 139, 5747-5754. DOI: 10.1039/c4an01325e. (b) Hurvois, J. P.; Moinet, C. Reactivity of ferrocenium cations with molecular oxygen in polar organic solvents: Decomposition, redox reactions and stabilization. J. Organomet. Chem. 2005, 690, 1829-1839. DOI: 10.1016/j.jorganchem.2005.02.009.

(35) Ferrocenium is known to be unstable in MeCN in the presence of air and water (see ref. 34). However, since samples of Cp${ }_{2} \mathbf{C o}^{+} @ 1 \mathbf{a}^{12+}$ were prepared with rigorously dry $\mathrm{CD}_{3} \mathrm{CN}$ in an air-free glovebox, we speculate that other decomposition pathways may be available for $\mathrm{Fc}^{+}$. Evidence supporting this possibility is shown in Figures S35 and S36.

(36) Redox-induced exchange of cations is important for lithium-ion batteries, electrocatalysis, and for understanding the fundamental redox properties of extended porous materials: (a) Manthiram, A. A reflection on lithium-ion battery cathode chemistry. Nat. Commun. 2020, 11, 1550. DOI: 10.1038/s41467-020-153550. (b) Liberman, I.; Shimoni, R.; Ifraemov, R.; Rozenberg, I.; Singh, C.; Hod, I. Active-Site Modulation in an Fe-Porphyrin-Based MetalOrganic Framework through Ligand Axial Coordination: Accelerating Electrocatalysis and Charge-Transport Kinetics. J. Am. Chem. Soc. 2020, 142, 1933-1940. DOI: 10.1021/jacs.9b11355. (c) Saouma, C. T.; Tsou, C.-C.; Richard S.; Ameloot, R.; Vermoortele, F.; Smolders, S.; Bueken, B.; DiPasquale, A. G.; Kaminsky, W.; Valdez, C. N.; De Vos, D. E.; Mayer, J. M. Sodium-coupled electron transfer reactivity of metal-organic frameworks containing titanium clusters: the importance of cations in redox chemistry. Chem. Sci. 2019, 10, 1322-1331. DOI: 10.1039/C8SC04138E. 
TOC Graphic

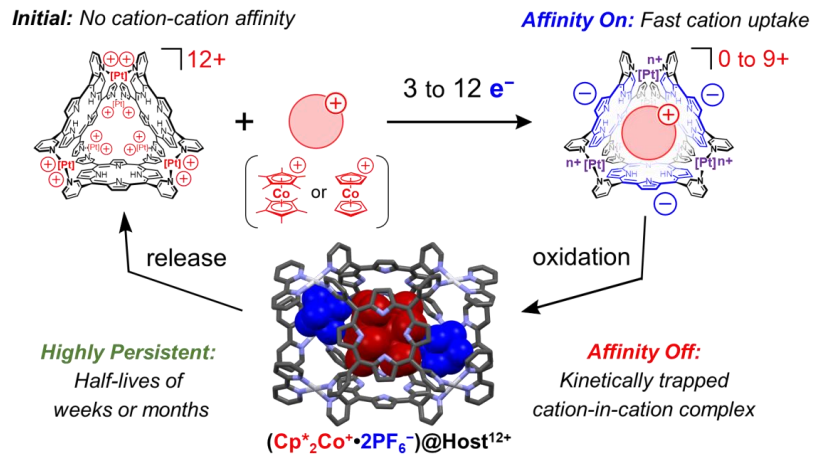

